\title{
Formation of Copper Nanoparticles in LTL Nanosized Zeolite: \\ Spectroscopic Characterization
}

\author{
A. Kharchenko, ${ }^{\mathrm{a}}$ V. Zholobenko, ${ }^{\mathrm{b}}$ A. Vicente, ${ }^{\mathrm{a}}$ C. Fernandez, ${ }^{\mathrm{a}}$ H. Vezin, ${ }^{\mathrm{c}}$ V. De Waele, ${ }^{\mathrm{c}}$ \\ and S. Mintova ${ }^{\mathrm{a}, *}$
}

áLaboratoire Catalyse et Spectrochimie (LCS), ENSICAEN, Université de Caen, CNRS, 14050 Caen, France

${ }^{\mathrm{b}}$ Keele University, Keele, Staffordshire ST5 5BG, UK

${ }^{c}$ Laboratoire de Spectrochimie Infrarouge et Raman (LASIR), Université de Lille, CNRS, UMR 8516, 59000 Lille, France

\begin{abstract}
The state of copper species stabilized in nanosized LTL zeolite subjected to various post-synthesis treatments was unveiled by a range of spectroscopic techniques. FTIR and UV-Vis studies demonstrated that the reduction process of copper in the LTL nanosized zeolite leads to the formation of different species including $\mathrm{Cu}^{2+}, \mathrm{Cu}^{+}$and $\mathrm{Cu}$ nanoparticle $(\mathrm{Cu}$ NPs). The adsorption of probe molecules (NO and $\mathrm{CO}$ ) was used to selectively monitor the copper species in the LTL nanosized zeolite upon oxidation and reduction post-synthesis treatments. Both the $\mathrm{Cu}^{2+}$ and $\mathrm{Cu}^{+}$species were probed by $\mathrm{NO}$ and $\mathrm{CO}$, respectively. The amount of $\mathrm{Cu}^{+}$in the LTL zeolite nanocrystals was about $43 \%$ as determined by FTIR, while the amount of $\mathrm{Cu}$ NPs was about $55 \%$ determined by the UV-Vis spectroscopic characterization. These results were complemented by EPR, ${ }^{29} \mathrm{Si}$ and ${ }^{63} \mathrm{Cu}$ MAS NMR spectroscopic data. The EPR spectroscopy was further applied to monitor the effective reduction of the $\mathrm{Cu}^{2+}$ species and their re-oxidation, while the ${ }^{63} \mathrm{Cu}$ MAS NMR verified the presence of $\mathrm{Cu}$ NPs in the LTL nanosized zeolite crystals.
\end{abstract}

\section{Introduction}

Metallic nanoparticles have attracted significant attention in catalysis due to their high activity and selectivity in many important chemical processes such as 
hydrogenation/dehydrogenation, ${ }^{1}$ isomerization, ${ }^{2}$ oxidation and reduction of $\mathrm{NO}_{\mathrm{x}}$ with hydrocarbons. ${ }^{3}$ High catalytic activity is attributed to a high proportion of atoms located at corners and edges with low coordination numbers and have the ability to activate substrates. ${ }^{4}$ The number of such atoms is increasing with the decrease of their particle size and it has frequently been reported that the catalytic activity increased when the particle size decreased. Most active catalysts generally contain particles smaller than $5 \mathrm{~nm}^{4}$ Substantial progress has been achieved in the synthesis of silver and gold nanomaterials with high catalytic performance. ${ }^{5,6}$ In this context, copper nanoparticles ( $\mathrm{Cu}$ NPs) with controlled size and shape are good alternative materials for catalysis because of their electronic structure, catalytic properties and lower cost. ${ }^{7}$ Copper NPs that adsorb in the visible range are of particular interest due to the possibility of their application in photocatalysis and plasmonic chemistry. ${ }^{8,9}$ However, one of the main drawbacks of small metallic nanoparticles is the low thermal stability and a tendency to sinter under harsh reaction conditions, limiting their application at a large scale. These obstacles can be overcome by confining the metal NP in inorganic matrix. Zeolites are promising hosts (matrix) for the stabilization of metal nanoparticles. ${ }^{4}$ The size, distribution and location of the NP are controlled by the steric constrains that originate from the zeolite topology, i.e. regular system of pores and cavities. ${ }^{10}$ Additionally, the zeolite structure imposes shape selectivity by limiting the diffusion of the molecules with the effective diameter bigger than the pore openings. However, the very existence of strong confinements, giving useful properties of the material, can affect their performance in catalysis and separation processes due to the slow mass transport through the micropores. Advances in the synthesis of nanosized zeolites provided materials in which the mean diffusion path is significantly lower, compared to their conventional micronsized counterparts. Indeed, the combination of superior properties on nanosized zeolites with the 
exceptional reactivity of metallic NP opens a way to the design of new advanced catalytic materials. ${ }^{11}$

Radiolytic and chemical approaches have been applied to control the formation of metal NPs in nanozeolites. ${ }^{9}$ Nanoparticles with a mean size varying from oligomeric clusters to large nm-sized nanoparticles have been obtained depending on the type of the zeolite framework, the metal content and the reduction conditions. In the case of copper, the final oxidation state $\left(\mathrm{Cu}^{\mathrm{II}}, \mathrm{Cu}^{\mathrm{I}}, \mathrm{Cu}^{0}\right)$ is influenced by the experimental conditions and the species can coexist within the zeolite pores. ${ }^{9}$

In our previous work, the formation of $\mathrm{Cu}$ NP in the nanosized LTL zeolite was investigated. The copper cations were introduced in zeolite nanocrystals via ion exchange after synthesis directly in the suspensions, and subsequently reduced with hydrazine monohydrate at room temperature. $^{12}$ The applied method was shown to be a promising route towards the preparation of copper NPs with desired properties due to its simplicity and reproducibility. By tailoring the synthesis conditions, it was possible to isolate supported copper nanoparticles with diverse sizes homogeneously distributed within the zeolite matrix. However, due to the nature of the synthesis process, interrupting the reduction reaction, in order to obtain the copper nanoparticles of desired size, would result in the formation of various copper species. Since the catalytic activity and selectivity can be affected by the presence of different active sites, it is important to identify both the $\mathrm{Cu}$ NPs and other $\mathrm{Cu}$ species present in the zeolite matrix. Both the targeted synthesis of copper active sites and their complementary characterization are crucial steps in the rational design of $\mathrm{Cu}$ NPs supported on zeolites that would allow the utilization of advantages offered by their unique properties.

FTIR of adsorbed probe molecules has been extensively employed to determine the state of supported metal species. ${ }^{13-15}$ It is important to note that the choice of a suitable probe 
molecule is crucial in the FTIR spectroscopy as it determines which surface property is tested. ${ }^{16}$ Often the use of different probe molecules in separate experiments, which provide complementary information, is a key to the comprehensive understanding of diverse species. $\mathrm{CO}$ and NO molecules can provide valuable information on the dispersion, coordination, and the oxidation state of supported metal species. In addition, the size of these test molecules allows site accessibility even in small zeolite cavities, whereas the experiments performed at liquid-nitrogen temperature afford the detection of species characterized by weak interaction with the probe, which cannot be detected at higher temperatures. ${ }^{16}$

The focus of this work is on spectroscopic characterization of $\mathrm{Cu}$ species supported on LTL zeolite, particularly by FTIR using $\mathrm{CO}$ and NO probe molecules; the chemical reduction with hydrazine was described extensively in our previous report. ${ }^{12}$ The choice of CO and NO was determined by their sensitivity to $\mathrm{Cu}^{+}$and $\mathrm{Cu}^{2+}$ species, respectively. Elucidating the nature of $\mathrm{Cu}$ species in zeolites is complex and usually demands a multi-technique approach. Therefore, the FTIR studies have been supplemented by EPR, ${ }^{29} \mathrm{Si}$ and ${ }^{63} \mathrm{Cu}$ MAS NMR and Diffuse Reflectance (DR) UV-Vis measurements. Indeed, EPR complements the information on the $\mathrm{Cu}^{2+}$ species, whereas the ${ }^{63} \mathrm{Cu}$ and ${ }^{29} \mathrm{Si}$ MAS NMR allow characterization of metallic copper species and changes in their environment. Additionally, DR UV-Vis is utilized to detect copper ions, metallic copper and different $\mathrm{Cu}-\mathrm{O}$ complexes.

\section{Experimental Part}

Nanosized K-LTL type zeolite $((\mathrm{Si} / \mathrm{Al}=3)$ with monomodal particle size distribution was

synthesized as described elsewhere. ${ }^{12}$ The as-prepared precursor suspensions were aged at room temperature for 24 hours prior to hydrothermal treatment $\left(170{ }^{\circ} \mathrm{C}\right.$ for 18 hours $)$. After the crystallization process was accomplished, the nanosized zeolite crystals were recovered by multistep centrifugation $(20000 \mathrm{rpm}, 40 \mathrm{~min})$ and washed with doubly distilled water reaching $\mathrm{pH}=7-8$ (sample is denoted as parent $\mathbf{L T L}$ ). Zeolite samples were ion-exchanged 
with copper nitrate $(0.1 \mathrm{M})$ in colloidal zeolite suspensions using solutions containing 0.3 mmol $\mathrm{Cu}^{2+} / \mathrm{g}$ zeolite to achieve $\sim 10 \%$ of $\mathrm{K}^{+}$cations exchange for copper. The ion-exchange process was carried out at room temperature for 2 hours, and then the zeolite was separated by multi-step centrifugation to remove the excess of copper ions (sample is denoted as $\mathbf{C u}^{2+}$ LTL). Next, the incorporated copper cations were reduced in zeolite suspension using excess of hydrazine $\left(\mathrm{Cu}^{2+} / 1000 \mathrm{~N}_{2} \mathrm{H}_{4}\right)$ under $\mathrm{N}_{2}$ atmosphere. The reaction was carried out at room temperature for 280 minutes achieving $\sim 56 \%$ reduction of $\mathrm{Cu}^{2+}$ to $\mathrm{Cu}^{0}$ in agreement with in situ UV-Vis studies. ${ }^{12}$ Subsequently, the solid was isolated by centrifugation and freeze-dried and the final product (sample is denoted as $\mathbf{C u}^{\mathbf{0}}$-LTL) was stored in the glove box in $\mathrm{Ar}$ atmosphere to prevent further $\mathrm{Cu}$ NPs oxidation. According to High Resolution Transmission Electron Microscopy (HRTEM) results, the copper nanoparticles are evenly distributed in the pores and on the surface of the LTL matrix with the particle size of $0.4-2.2 \mathrm{~nm}$. A detailed description of this procedure along with the structural and textural characterization of the obtained $\mathrm{Cu}-\mathrm{LTL}$ zeolites has been reported previously. ${ }^{12}$

FTIR spectra of CO and NO adsorbed on zeolite samples were recorded using a ThermoNicolet Nexus instrument by accumulating of 128 scans at a spectral resolution of $4 \mathrm{~cm}^{-1}$. Self-supported pellets (diameter $(\mathrm{d})=16 \mathrm{~mm}$, weight $(\mathrm{m})=20 \mathrm{mg}$ ) were prepared from powdered samples and treated in situ in the transmission IR cells directly. Prior to the IR measurements, the samples were activated under oxygen or hydrogen atmosphere, or in vacuum at $673-723 \mathrm{~K}$ to study the effects of oxidation and reduction pretreatment on the state of copper species in order to identify different types of sites. After the pretreatment, icreasing calibrated doses of $\mathrm{CO}$ and NO were introduced into the IR cell up to $1600 \mu \mathrm{mol} / \mathrm{g}$ and $2000 \mu \mathrm{mol} / \mathrm{g}$, respectively. In the case of CO adsorption, the system was later evacuated at $100 \mathrm{~K}, 293 \mathrm{~K}$ and $423 \mathrm{~K}$ to monitor the stability of copper species. The deconvolution of the spectra has been performed with MagicPlot software using Gaussian function. The peak 
positions have been determined using the second derivative and fixed for all spectra in order to fit the individual $\mathrm{CO}$ bands (Figure S 1).

The reduction of copper species was also studied by variable temperature EPR carried out at X-band (9.64 GHz) using a Brüker ELEXSYS E580 FT spectrometer. The state of copper was also characterized by diffuse reflectance UV-Vis spectroscopy utilizing a Varian Cary 4000 spectrophotometer. ${ }^{63} \mathrm{Cu}$ and ${ }^{29} \mathrm{Si}$ MAS NMR spectra were recorded on Bruker Avance III-HD $500 \mathrm{MHz}(11.7 \mathrm{~T})$ and $400 \mathrm{MHz}(9.4 \mathrm{~T})$ spectrometers, respectively. ${ }^{63} \mathrm{Cu}$ MAS NMR was done with a $90^{\circ}$ pulse of $2 \mu$ s and a recycle of delay of 5 s. 26348 scans were made to accumulate the signal with a very broad spectral width. For ${ }^{29} \mathrm{Si}$ MAS NMR experiments, single pulse excitation with pulse lengths of $7.0 \mu$ s ( $30^{\circ}$ flip angle) and $60 \mathrm{~s}$ recycling delay were used. T1 measurements were performed using inversion recovery $(\pi-$ tau- $\pi / 2)$ sequence. The pulse length was set to $6(\pi / 2)$ and $10.9 \mu$ s $(\pi)$ and different tau values in a range from 50 $\mu \mathrm{s}$ to $20 \mathrm{~s}$ were acquired. Topspin software, from Bruker, was used to extract T1 values for each sample. Copper experiments were performed with 4-mm outer diameter zirconia rotors and a spinning speed of $12 \mathrm{kHz}$, while ${ }^{29} \mathrm{Si}$ experiments were performed with a $7 \mathrm{~mm}$ zirconia rotor and a spinning speed of $4.5 \mathrm{kHz}$. Tetra-methylsilane (TMS) and $\mathrm{CuCl}$ were used as chemical shift reference for ${ }^{29} \mathrm{Si}$ and ${ }^{63} \mathrm{Cu}$ nucleus, respectively.

\section{Results and discussion}

\section{FTIR spectroscopy study of copper containing zeolite samples}

The FTIR spectra $\left(\mathrm{OH}\right.$ stretching region) of the $\mathrm{Cu}^{2+}$-LTL and $\mathrm{Cu}^{0}$-LTL samples after activation in vacuum at $673 \mathrm{~K}$ are presented in Figure 1. Both materials exhibit a band at $3747-3744 \mathrm{~cm}^{-1}$, which is characteristic of the isolated external silanol groups. ${ }^{16}$ High relative intensity of this band reflects the small size of the crystals that has already been reported in the literature as the spectral characteristic of the nanosized zeolites with well- 
developed external surface area. The $\mathrm{Cu}^{0}$-LTL sample exhibits additional bands at 3661 and $3628 \mathrm{~cm}^{-1}$, that can be assigned to extra-framework Al-sites and bridged hydroxyl $\equiv \mathrm{Si}(\mathrm{OH}) \mathrm{Al} \equiv$ groups, respectively. ${ }^{15-17}$ The presence of the latter can be explained by the generation of bridging $\mathrm{OH}$-groups following the chemical reduction of $\mathrm{Cu}^{2+}$ species to $\mathrm{Cu}^{0}$. Appearance of extra framework aluminium and associated Al-OH groups could be explained by the partial degradation of the formed structure during high temperature activation, which is common for zeolites with low $\mathrm{Si} / \mathrm{Al}$ ratios. ${ }^{18}$ However, these effects are not significant, as the intensity of the bands at 3661 and $3628 \mathrm{~cm}^{-1}$ is low.

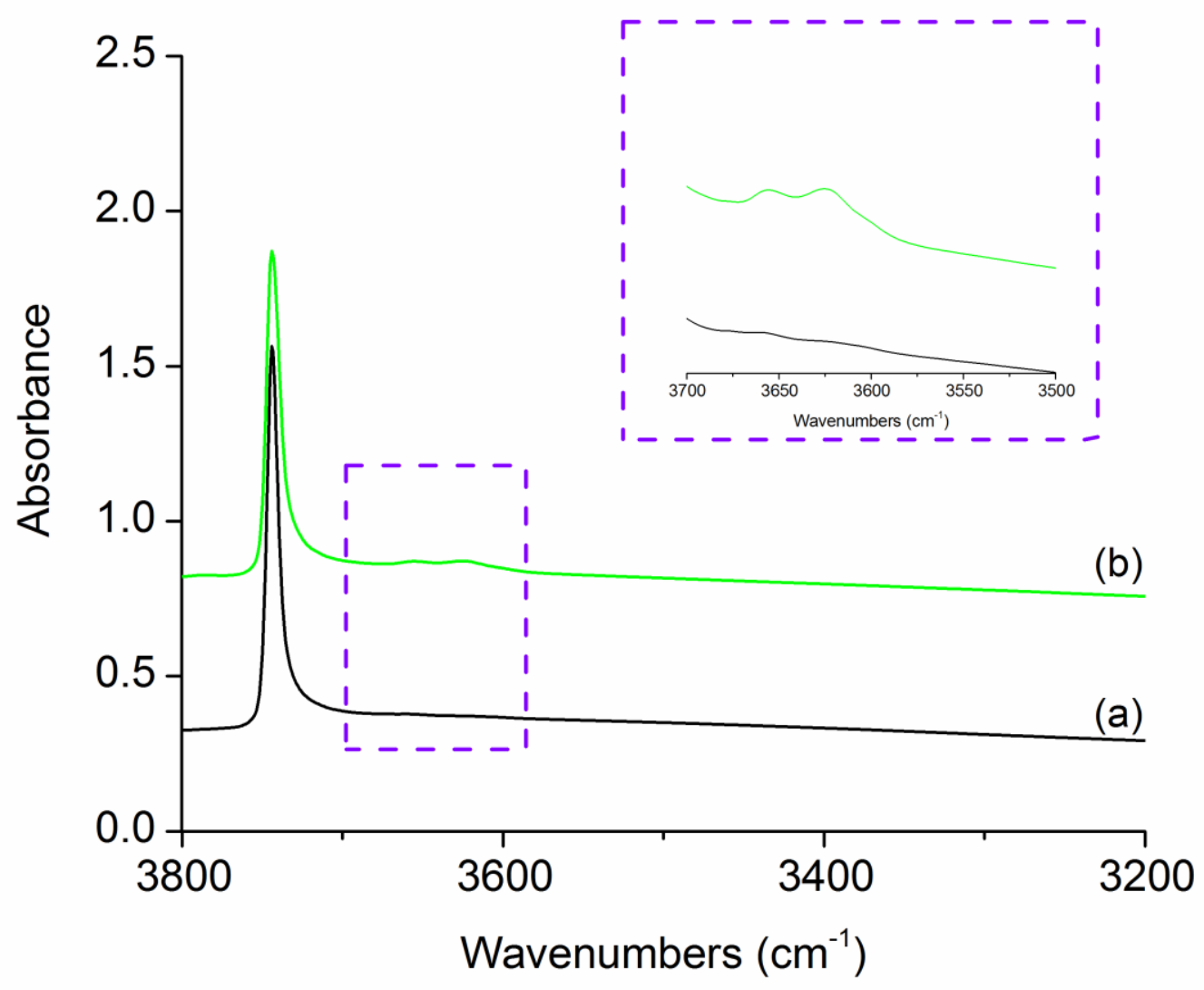

Figure 1 FTIR spectra in the OH-region of Cu-LTL samples collected at $300 \mathrm{~K}$ after activation at $673 \mathrm{~K}$ and $723 \mathrm{~K}$ : (a) $\mathrm{Cu}^{2+}$-LTL and (b) $\mathrm{Cu}^{0}-\mathrm{LTL}$; Inset: spectra in the range $3500-3700 \mathrm{~cm}^{-1}$.

CO adsorption on copper containing zeolite samples: FTIR spectroscopy study 
The revealing the state of copper in the $\mathrm{Cu}$ exchanged zeolites is of primary importance for their potential applications. It is essential to control the state of the copper species $\left(\mathrm{Cu}^{0}, \mathrm{Cu}^{+}\right.$ and $\mathrm{Cu}^{2+}$ ions) and the amount of desired $\mathrm{Cu}$ NPs, that are necessary to realize a targeted reaction and limit the number of the undesired processes. $\mathrm{CO}$ adsorption on metal centres monitored by FTIR spectroscopy has been widely utilized to characterize their structure and electronic properties. The frequency shifts, as compared to the vibration of the gaseous $\mathrm{CO}$ at $2143 \mathrm{~cm}^{-1}$, can give information about the oxidation state, coordination number and the metal particle size. In the case of copper ions, $\mathrm{CO}$ is preferentially adsorbed on $\mathrm{Cu}^{+}$ions since the formed carbonyl complex is stabilized by both $\sigma$ bonding and $\pi$-back donation. ${ }^{19}$ As has been shown previously, ${ }^{13,19,20}$ mainly electrostatic forces bond $\mathrm{CO}$ to $\mathrm{Cu}^{2+}$ ions, while the $\sigma$ component of the bond is negligible, and there is no $\pi$ back-donation. The carbonyls of $\mathrm{Cu}^{2+}$ ions are typically detected at low temperature or at high equilibrium pressure of CO (bands higher than $2160 \mathrm{~cm}^{-1}$ ); these bands easily vanish upon increasing of the temperature. After subsequent the cooling step to $77 \mathrm{~K}$, these bands typically do not re-appear due to the reduction of $\mathrm{Cu}^{2+}$ with $\mathrm{CO}$ at elevated temperature treatment. ${ }^{21}$ Additionally, $\mathrm{CO}$ forms mainly a $\pi$-bond with $\mathrm{Cu}^{0}$ atoms, and the resulting complexes are relatively unstable. $\mathrm{CO}$ stretching frequencies of $\mathrm{Cu}^{+}-\mathrm{CO}$ and $\mathrm{Cu}^{0}-\mathrm{CO}$ complexes fall in the same spectral region, 2110-2080 $\mathrm{cm}^{-1}$, making their discrimination difficult. Since the $\mathrm{Cu}$ NPs have been identified and characterized in our previous work (e.g. using TEM and UV-vis spectroscopy), ${ }^{12}$ the focus of this study is to characterize the residual copper species.

$\mathrm{CO}$ adsorption on copper containing zeolite samples has been initially studied at low temperature $(100 \mathrm{~K})$ by introduction of increasing calibrated doses of gas from 30 to 1600 $\mu \mathrm{mol} / \mathrm{g}$. The IR spectra (C-O-stretching region) of $\mathrm{Cu}-\mathrm{LTL}$ samples pretreated under various conditions are shown in Figure 2, and the observed $\mathrm{CO}$ stretching frequencies are summarized in Table 1. Different pretreatment conditions have been used to identify the 
spectral features ascribed to specific species. Careful spectral deconvolution has allowed to differentiate them and follow their evolution with increasing $\mathrm{CO}$ pressure.

Adsorption of $\mathrm{CO}$ on the $\mathrm{Cu}^{2+}$-LTL sample, activated under $\mathrm{O}_{2}$ atmosphere, (Figure 2A) firstly leads to the appearance of intense bands at $2140 \mathrm{~cm}^{-1}$ and $2126 \mathrm{~cm}^{-1}$ attributed to $\mathrm{Cu}^{+}-$ $\mathrm{CO}$ complexes in different locations in the zeolite framework. The low intense band at 2190 $\mathrm{cm}^{-1}$ is assigned to $\mathrm{Cu}^{2+}-\mathrm{CO}$ species. ${ }^{22,23}$ After the introduction of $200 \mu \mathrm{mol} / \mathrm{g} \mathrm{CO}$, two bands at $2163 \mathrm{~cm}^{-1}$ and $2150 \mathrm{~cm}^{-1}$ with a shoulder at $2121 \mathrm{~cm}^{-1}$, that rise simultaneously at higher coverage, are also detected. These bands have been assigned to $\mathrm{C}-\mathrm{O}$-stretching of $\mathrm{K}^{+} \ldots \mathrm{CO}$ adducts and oxygen-bonded CO. ${ }^{13,24}$ The band $2163 \mathrm{~cm}^{-1}$ could also be ascribed as the interaction of $\mathrm{CO}$ with the silanol $\mathrm{OH}$ groups at low temperature. ${ }^{13}$ The shoulder at $2177 \mathrm{~cm}^{-1}$ indicates the interaction of $\mathrm{CO}$ with bridging $\mathrm{OH}$ groups or, which is more likely in this system, the formation of the di-carbonyl $\mathrm{Cu}^{+}-(\mathrm{CO})_{2}$ complexes, ${ }^{13}$ since no $\mathrm{OH}$ bridging groups are observed for the oxidized samples (Figure 1).

The frequencies of the bands in the IR spectra collected for $\mathrm{Cu}^{2+}$-LTL sample, activated at $673 \mathrm{~K}$ in vacuum are similar to those for oxidized sample (Figure 2B). However, the evolution of their intensities with the coverage level differs significantly. The bands at 2140, 2126 and $2177 \mathrm{~cm}^{-1}$, assigned to $\mathrm{Cu}^{+}-\mathrm{CO}$ and $\mathrm{Cu}^{+}-(\mathrm{CO})_{2}$, appear first, whereas the peaks at 2190,2163 and $2150 \mathrm{~cm}^{-1}$ appear at higher coverage after the introduction of $200 \mu \mathrm{mol} / \mathrm{g} \mathrm{CO}$. In both cases, a low intensity peak at $2103 \mathrm{~cm}^{-1}$ appears at high $\mathrm{CO}$ coverage and is assigned to $\mathrm{CO}$ adsorbed on $\mathrm{Cu}^{0}$ species. ${ }^{13}$ Figures $2 \mathrm{~A}$ and $2 \mathrm{~B}$ show a significant degree of oxidation of copper to $\mathrm{Cu}^{2+}$ in the presence of $\mathrm{O}_{2}$, however, $\mathrm{Cu}^{+}$species are still preserved. The presence of $\mathrm{Cu}^{+}-\mathrm{CO}$ and $\mathrm{Cu}^{0}-\mathrm{CO}$ species in the sample treated under oxygen and in vacuum can be explained by so called "auto-reduction" of $\mathrm{Cu}^{2+}$ at high temperature during the dehydration of the divalent $\mathrm{Cu}^{2+}\left(\mathrm{H}_{2} \mathrm{O}\right)_{n}$ complexes, ${ }^{25,26}$ or by its reduction in the presence of $\mathrm{CO}$, that can already occur at $77 \mathrm{~K}^{21}$ 


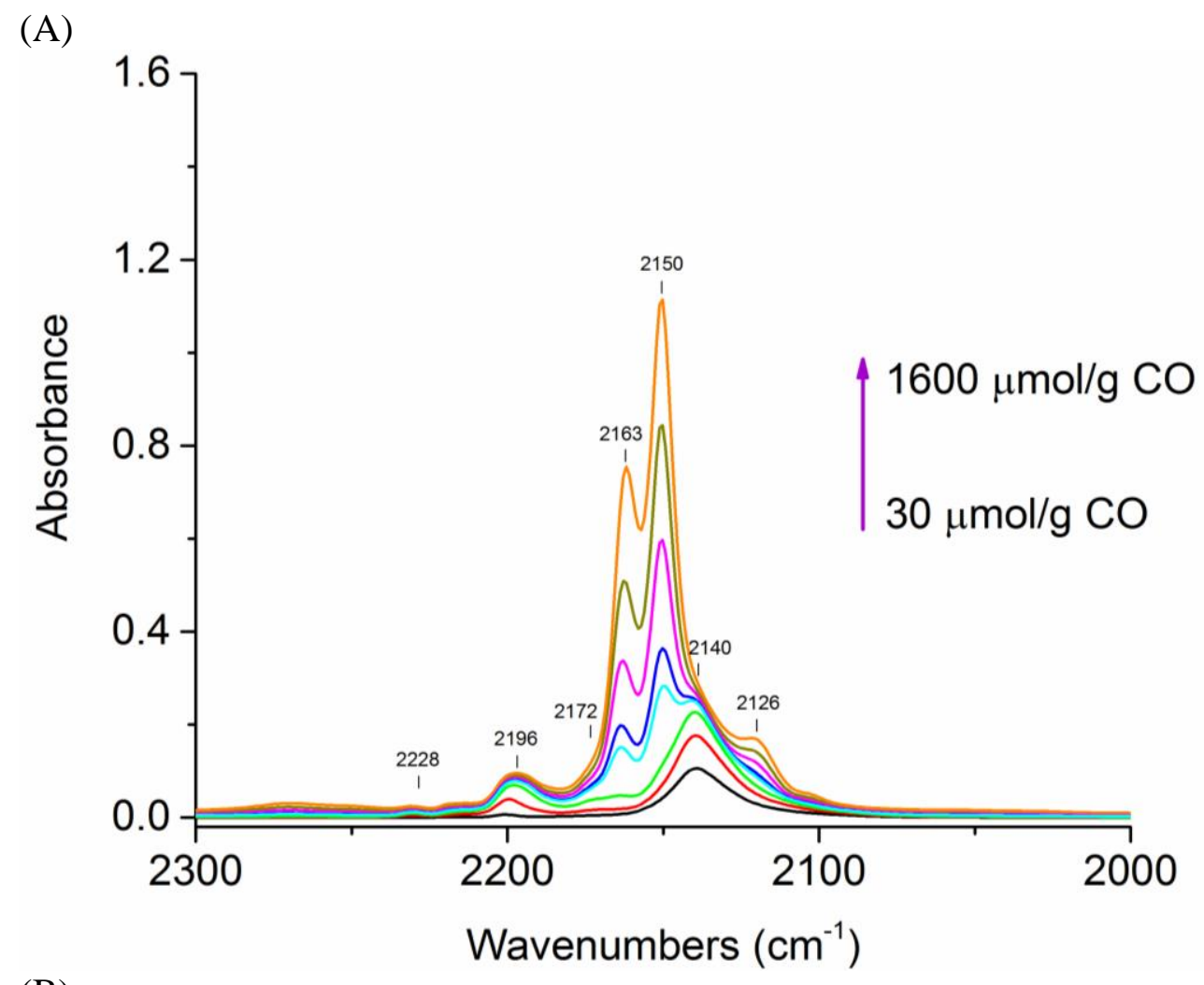

(B)

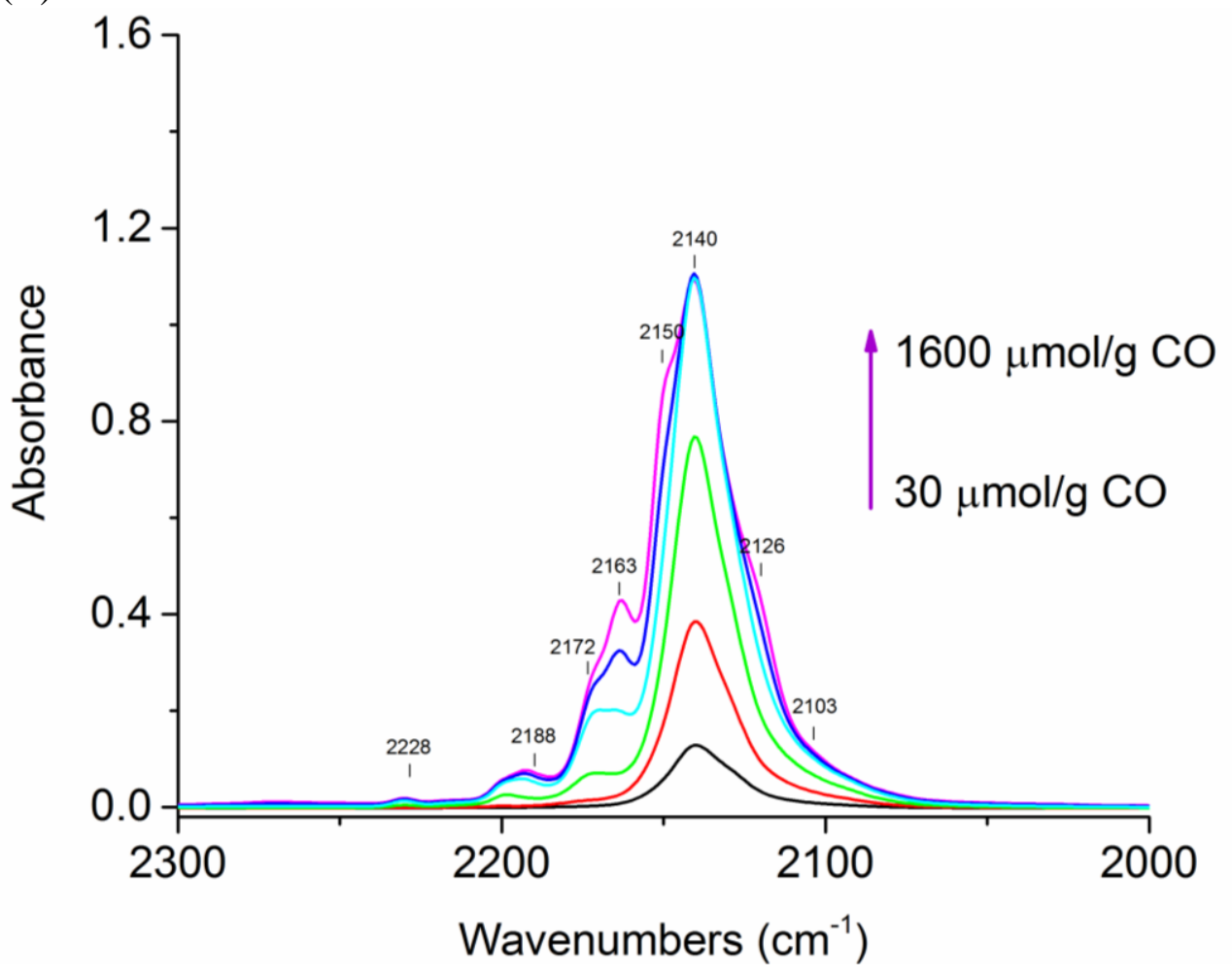


(C)

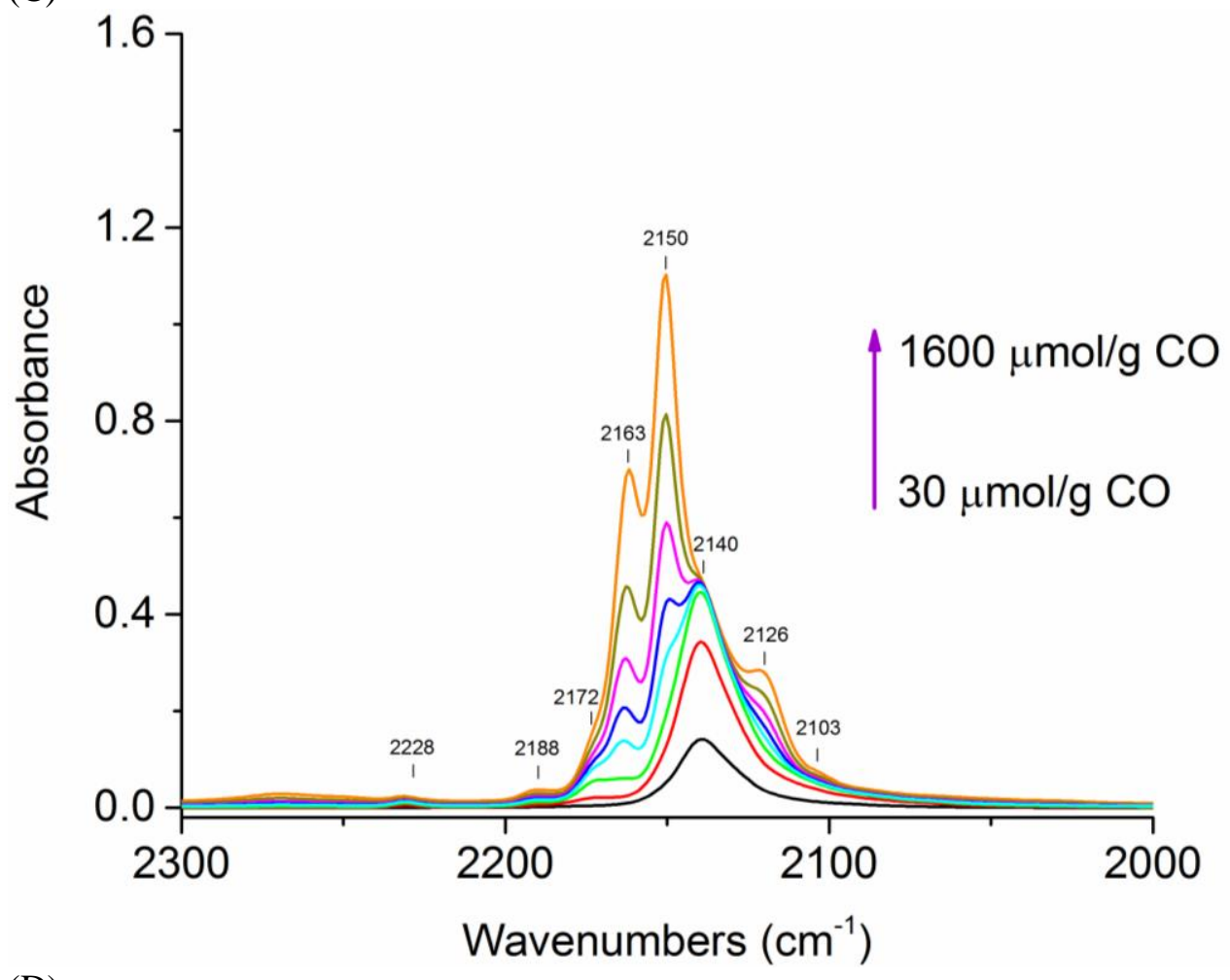

(D)

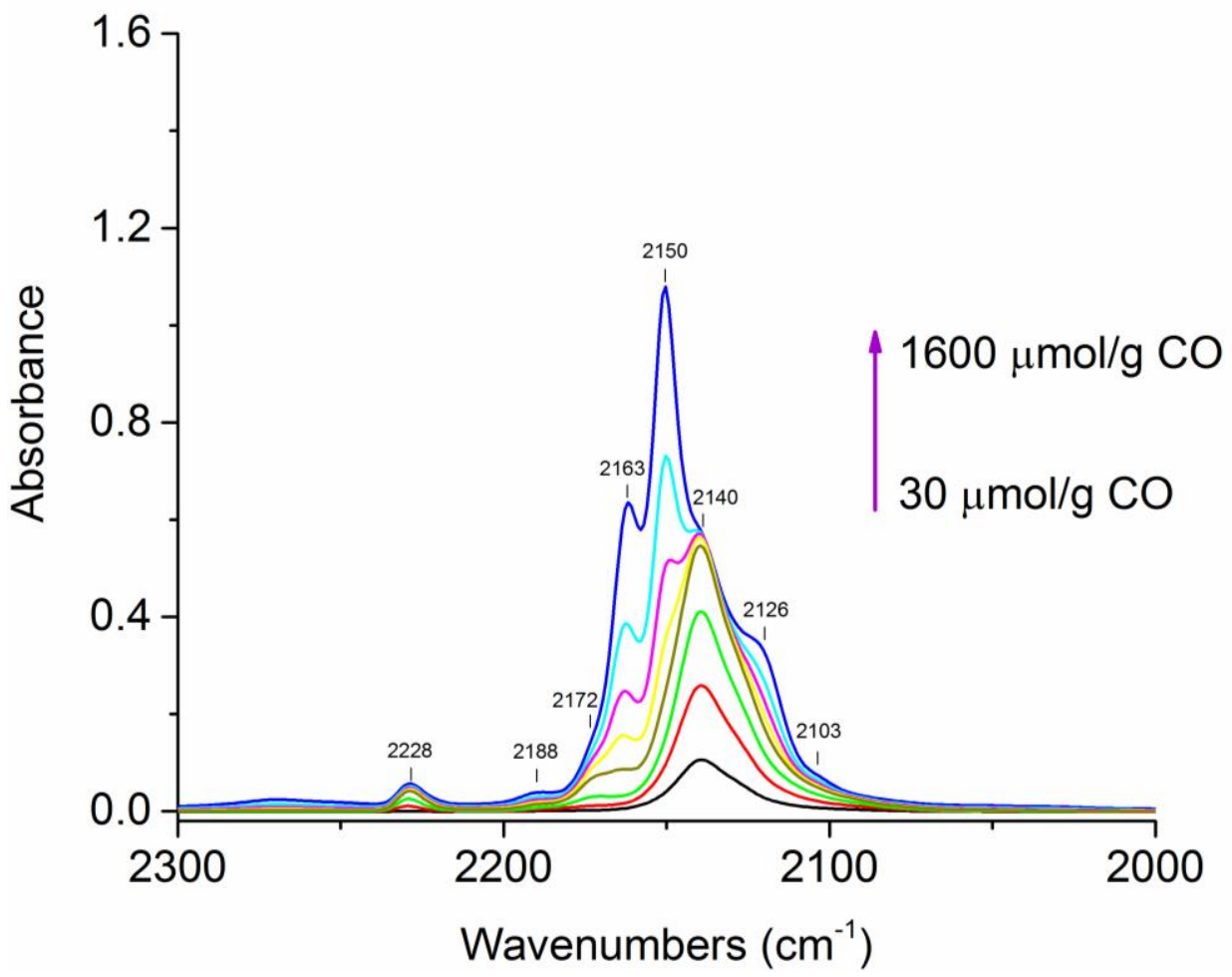

Figure 2 Evolution of the IR spectra of copper containing LTL in the range $2300-2000 \mathrm{~cm}^{-1}$ upon interaction with increasing doses of $\mathrm{CO}(30-1600 \mu \mathrm{mol} / \mathrm{g})$ at $100 \mathrm{~K}$. Sample $\mathrm{Cu}^{2+}$-LTL activated at $673 \mathrm{~K}$ in $\mathrm{O}_{2}(\mathrm{~A})$, in vacuum (B), in $\mathrm{H}_{2}(\mathrm{C})$, and sample $\mathrm{Cu}^{0}$-LTL reduced with $\mathrm{N}_{2} \mathrm{H}_{4}$, activated at 723 $\mathrm{K}$ in vacuum $(\mathrm{D})$. 
Table 1 Frequencies and assignment of the $\mathrm{C}-\mathrm{O}$ stretching frequencies observed in this study.

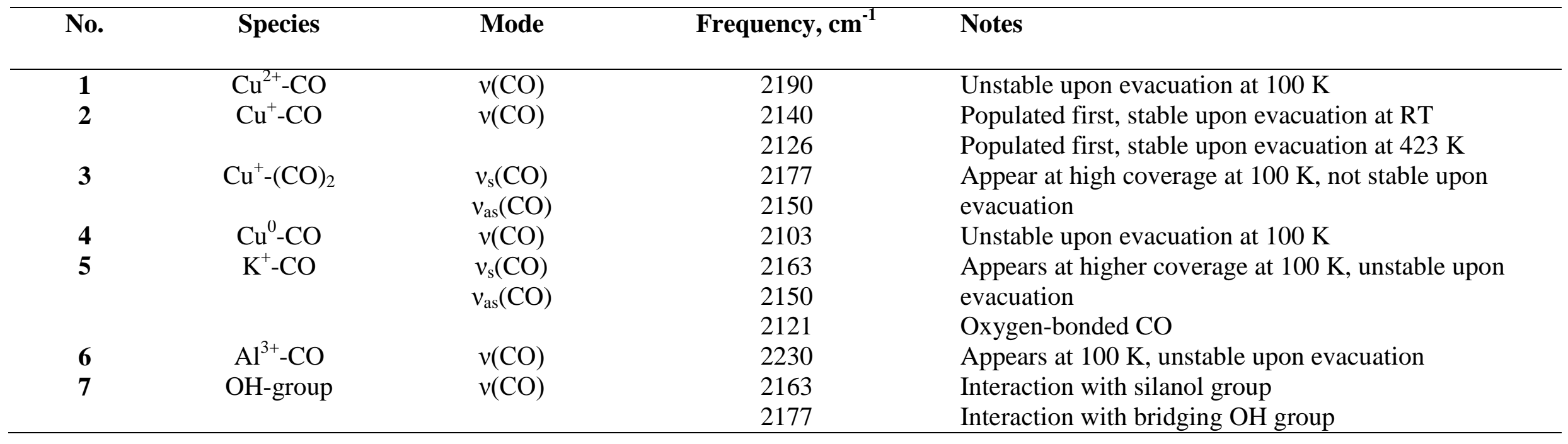


Figures $2 \mathrm{C}$ and 2D present spectra of $\mathrm{Cu}^{2+}$-LTL pretreated in $\mathrm{H}_{2}$ and $\mathrm{Cu}^{0}$-LTL reduced with hydrazine and activated at $723 \mathrm{~K}$ in vacuum, respectively. These two samples show almost identical spectra with similar distribution of band intensities and are qualitatively similar to the spectra in Figure 2A and 2B. The intensity of the band at $2140 \mathrm{~cm}^{-1}$ is intermediate between the level of Figure 2A and 2B, and the bands at $2190 \mathrm{~cm}^{-1}$ and $2177 \mathrm{~cm}^{-1}$, attributed to $\mathrm{Cu}^{2+}-\mathrm{CO}, \mathrm{Cu}^{+}$di-carbonyls and possibly to bridging $\mathrm{OH}$ groups, exhibit a lower intensity. This is a consequence of the reduction treatments applied to these two samples and the very weak interaction of $\mathrm{CO}$ with the copper in $(2+)$ oxidation state. Another important difference, when compared to Figure $2 \mathrm{~B}$, is the lower intensity of the bands at $2140 \mathrm{~cm}^{-1}$ and $2126 \mathrm{~cm}^{-1}$ $\left(\mathrm{Cu}^{+}-\mathrm{CO}\right)$, and a more pronounced peak at $2103 \mathrm{~cm}^{-1}$, assigned to $\mathrm{Cu}^{0}-\mathrm{CO}$ that appears at lower pressure.

The stability of copper carbonyls was tested by progressive evacuation at $100 \mathrm{~K}$ (Figures S2 and Figure 3) at higher temperatures. Only the bands at $2140 \mathrm{~cm}^{-1}$ and $2126 \mathrm{~cm}^{-1}$, attributed to $\mathrm{Cu}^{+}-\mathrm{CO}$ complexes (Figure 3), remain after evacuation at ambient temperature. After evacuation at $423 \mathrm{~K}$, a prominent peak at $2126 \mathrm{~cm}^{-1}$ still remains while the intensity of the band at $2140 \mathrm{~cm}^{-1}$ decreases drastically. ${ }^{13}$

The results show that the main differences between the above four samples are the intensities of the bands at $2140 \mathrm{~cm}^{-1}$ and $2126 \mathrm{~cm}^{-1}$, both assigned to $\mathrm{Cu}^{+}-\mathrm{CO}$ interaction. Considering that the amount of copper is the same in all samples, the spectral changes can be assigned to the increased number of $\mathrm{CO}$ molecules coordinated to $\mathrm{Cu}$ NPs. This agrees with the literature data, showing that high temperature reduction of copper exchanged zeolites leads to the formation of $\mathrm{Cu}$ NPs. This is consistent with our previous findings demonstrating the generation of $\mathrm{Cu}$ NPs in $\mathrm{Cu}^{2+}$-LTL sample reduced with hydrazine in aqueous media. ${ }^{12}$ It should be noted that all samples before and after reduction contain $\mathrm{Cu}^{+}$-species that firstly interact under introducing $\mathrm{CO}$. 


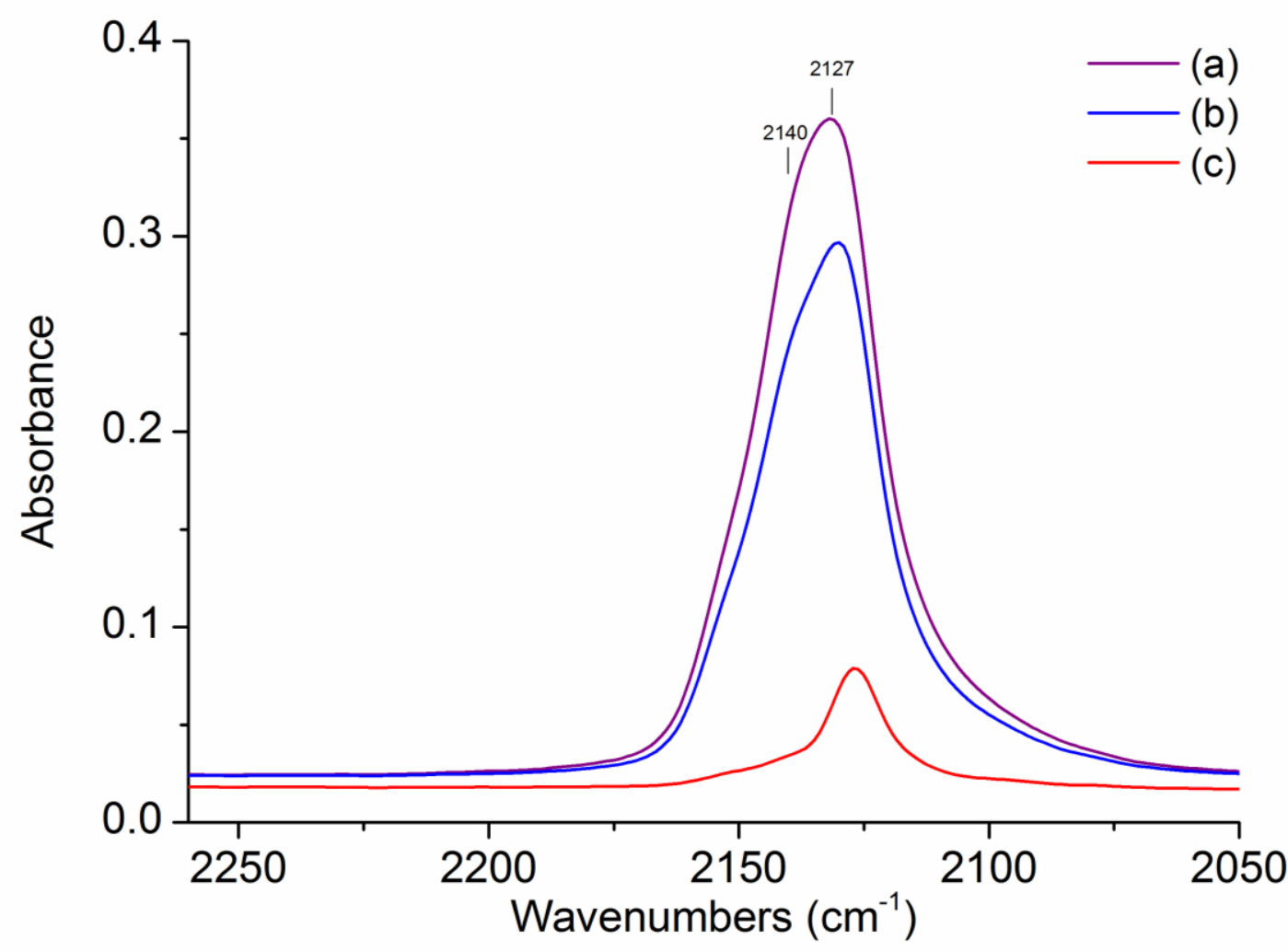

Figure 3 IR spectra $\left(2300-2000 \mathrm{~cm}^{-1}\right)$ of the sample reduced with hydrazine and activated at $723 \mathrm{~K}$ in vacuum upon evacuation at RT (a), after $10 \mathrm{~min}$ at RT (b) and after heating at $423 \mathrm{~K}$ (c).

FTIR spectroscopy of adsorbed $\mathrm{CO}$ can be used to estimate the concentration of $\mathrm{Cu}^{+}$sites in the samples, and consequently the $\mathrm{Cu}^{+} / \mathrm{Cu}_{\text {total }}$ ratio. The integrated areas of the $v(\mathrm{CO})$ band at $2140 \mathrm{~cm}^{-1}$ and $2126 \mathrm{~cm}^{-1}$ after deconvolution of the recorded spectra have been determined. Assuming the $\mathrm{CO}$ molar absorption coefficient for the band at $2140 \mathrm{~cm}^{-1}$ as $13.5 \mathrm{~cm} / \mu \mathrm{mol}$ and for the band at $2126 \mathrm{~cm}^{-1}$ as $10 \mathrm{~cm} / \mu \mathrm{mol}\left(\operatorname{Ref}{ }^{13}\right)$, and the surface of the pellet as $2 \mathrm{~cm}^{2}$, the concentration of $\mathrm{Cu}^{+}$species is calculated by the following equation:

$$
n=\frac{\text { Area } \times S_{\text {pellet }}}{\varepsilon \times m_{\text {pellet }}},
$$

where $\mathrm{n}$ is the concentration of $\mathrm{Cu}^{+}(\mu \mathrm{mol} / \mathrm{g})$; Area is the integrated area of the $\mathrm{CO}$ adsorption bands at $2140 \mathrm{~cm}^{-1}$ and $2126 \mathrm{~cm}^{-1}$ obtained after the deconvolution $\left(\mathrm{cm}^{-1}\right) ; \varepsilon$ is the 
molar absorption coefficient of $\mathrm{CO}$ on $\mathrm{Cu}^{+}(\mathrm{cm} / \mu \mathrm{mol}) ; \mathrm{S}_{\text {pellet }}$ is the surface of the pellet (2 $\left.\mathrm{cm}^{2}\right) ; \mathrm{m}_{\text {pellet }}$ is the mass of the pellet $(\mathrm{g})$.

The evolution of the integrated areas of the $v(\mathrm{CO})$ bands at 2140 and $2126 \mathrm{~cm}^{-1}$ as a function of the introduced $\mathrm{CO}$ display an incremental increase followed by a plateau as shown in Figure 4A-B. Therefore, considering the $\mathrm{Cu}^{+}: \mathrm{CO}$ stoichiometry to be $1: 1,{ }^{27}$ the amount of $\mathrm{CO}$ adsorbed on $\mathrm{Cu}^{+}$at "saturation" can be determined from the intersection of two trend lines built from the slope and the plateau. The results reported in Table S1 confirm the high stability of $\mathrm{Cu}^{+}$in the LTL zeolite since $\mathrm{Cu}^{+}$is presented in all the samples in significant amounts. The quantity of $\mathrm{Cu}^{+}$species in the $\mathrm{Cu}^{0}$-LTL sample is almost $44 \%$ of the total copper present in the sample, which is in agreement with the UV-Vis measurements ${ }^{12}$ showing that the relative amount of $\mathrm{Cu}^{0}$ species is about $55 \%$ with respect to the total copper loading. 
(A)

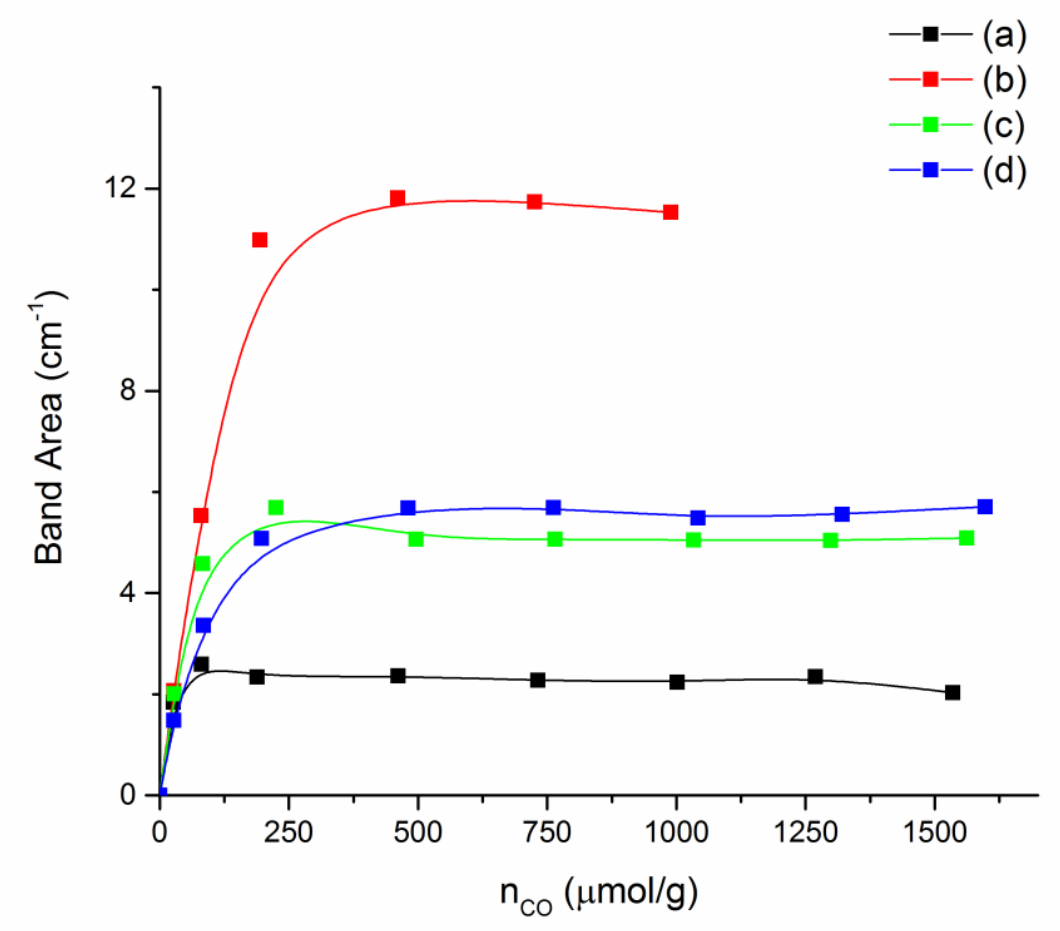

(B)

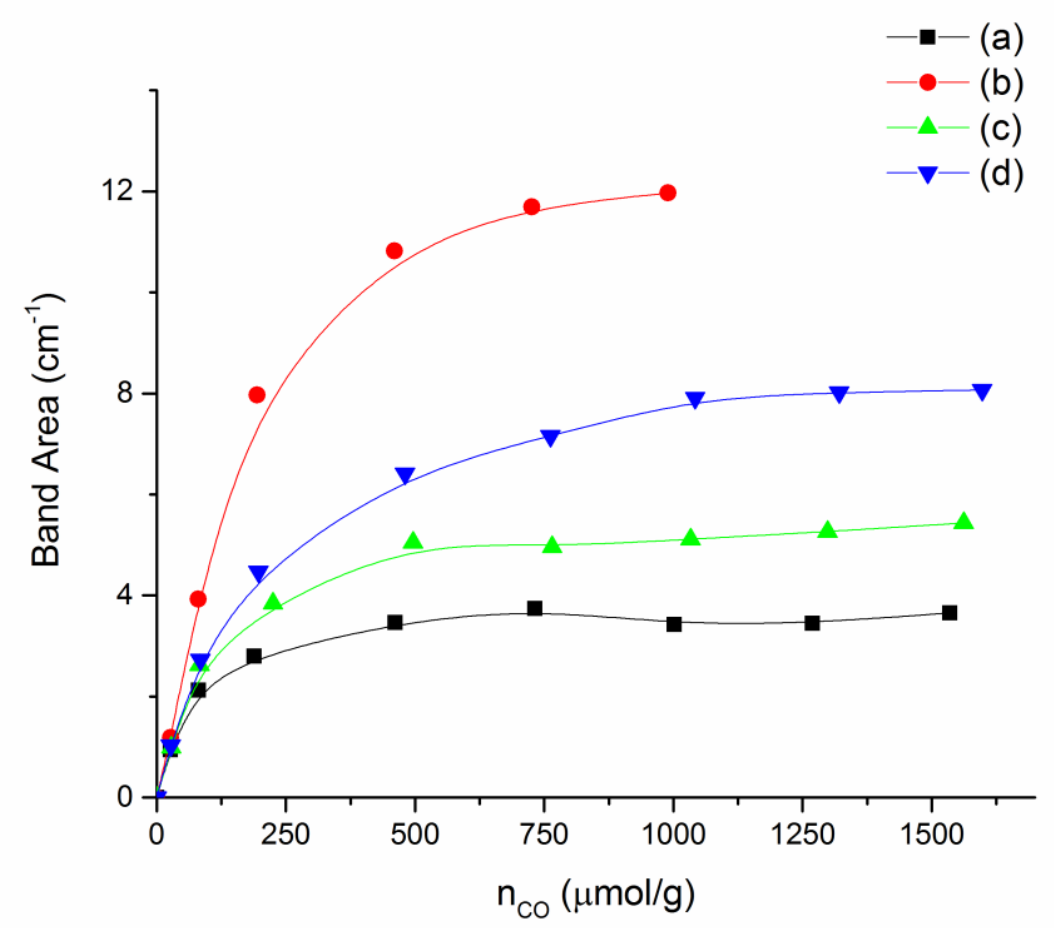

Figure 4. (A) Integrated area of the $v(\mathrm{CO})$ band at $2140 \mathrm{~cm}^{-1}$ and (B) integrated area of the $v(\mathrm{CO})$ band at $2126 \mathrm{~cm}^{-1}$ bound to copper as a function of $\mathrm{CO}$ concentration introduced for a set of samples: (a) $\mathrm{Cu}^{2+}$-LTL activated at $673 \mathrm{~K}$ in $\mathrm{O}_{2}$, (b) $\mathrm{Cu}^{2+}$-LTL activated at $673 \mathrm{~K}$ in vacuum, (c) $\mathrm{Cu}^{2+}$-LTL activated at $673 \mathrm{~K}$ in $\mathrm{H}_{2}$ and (d) $\mathrm{Cu}^{0}$-LTL activated at $723 \mathrm{~K}$ in vacuum 


\section{NO adsorption on copper containing zeolite samples: FTIR spectroscopy study}

The $\mathrm{Cu}^{2+}$ cations form stronger bonds with NO than with $\mathrm{CO}$. As a result, surface $\mathrm{Cu}^{2+}{ }_{-} \mathrm{NO}$ species are easily formed at room temperature and detected in the IR region $1964-1845$ $\mathrm{cm}^{-1}$. NO bonds predominantly by a $\sigma$-bond to the cations and the higher the N-O stretching frequency is the stronger is the bond. However, $\mathrm{NO}$ molecule has one more electron than $\mathrm{CO}$ which makes $\pi$-back donation more difficult. As a result, the $\mathrm{Cu}^{+}-\mathrm{NO}$ species are not stabilized by a $\sigma-\pi$ synergistic effect and are considered unstable. ${ }^{19}$ It should also be mentioned that to the best of our knowledge there is no literature data published on the FTIR spectra of the interaction of nitric oxide with $\mathrm{Cu}$ NPs.

The stepwise adsorption of calibrated doses of NO has been carried out at low temperature on the same series of samples as for CO adsorption. The IR spectra contain the groups of bands in the $1980-1850 \mathrm{~cm}^{-1}$ and $1850-1650 \mathrm{~cm}^{-1}$ regions (Figure 5A-D). The band positions and their assignment ${ }^{14}$ are summarized in Table 2. The bands observed at 1953, 1938, 1905, 1886 $\mathrm{cm}^{-1}$ are characteristic of $\mathrm{Cu}^{2+}-\mathrm{NO}$ species and probably correspond to four different $\mathrm{Cu}^{2+}$ sites. According to the literature, ${ }^{14,28}$ the intense bands at lower frequencies can be assigned to isolated $\mathrm{Cu}^{2+}$ ions, while the bands at higher frequencies belong to nitrosyls formed with associated $\mathrm{Cu}^{2+}-\mathrm{O}-\mathrm{Cu}^{2+}$ sites or isolated $\mathrm{Cu}^{2+}$ cations in the square planar coordination. As shown in Figure 5, the intensity of the bands with lower frequency $\left(1886 \mathrm{~cm}^{-1}\right)$ are less affected by the sample treatment in vacuum or in $\mathrm{H}_{2}$. Indeed, the isolated $\mathrm{Cu}^{2+}$ sites are expected to be more difficult to reduce. ${ }^{29-31}$ The second set of bands includes peaks at 1825 , 1810, 1797 and $1730 \mathrm{~cm}^{-1}$, that generally represent the interaction of $\mathrm{NO}$ with $\mathrm{Cu}^{+}$-sites. ${ }^{14}$ They can be assigned to $\mathrm{Cu}^{+}-\mathrm{NO}$ mono-nitrosyls (peaks at 1810 and $1797 \mathrm{~cm}^{-1}$ ) which have been previously observed in zeolite $\mathrm{Y}$, and to $\mathrm{Cu}^{+}-(\mathrm{NO})_{2}$ di-nitrosyls characterized by a doublet with $v_{\mathrm{s}}$ and $v_{\mathrm{as}}$ at 1825 and $1730 \mathrm{~cm}^{-1}$, respectively which evolve with increasing NO pressure. $^{14,31}$ 
It should also be mentioned that other bands have been observed in the spectra. The peaks at $1770 \mathrm{~cm}^{-1}$ and $1863 \mathrm{~cm}^{-1}$ stay for cis- $\left(\mathrm{N}_{2} \mathrm{O}_{2}\right)$ weakly adsorbed in the zeolite channels, that appears due to isomerization of NO at low temperatures. ${ }^{17,29,32}$ The peaks centred at 1886 $\mathrm{cm}^{-1}$ and $1874 \mathrm{~cm}^{-1}$ become visible in the spectra of $\mathrm{Cu}^{0}$-LTL sample, these are assigned to $\mathrm{K}^{+} \cdots \mathrm{NO}$ monomers (Figure 5C). ${ }^{17}$ They are masked in the case of $\mathrm{Cu}^{2+}$-LTL pretreated in $\mathrm{O}_{2}$ or under vacuum by $\mathrm{Cu}^{2+}-\mathrm{NO}$ species (Figure 5A,B). All four samples contain the peak at $2245 \mathrm{~cm}^{-1}$, which has been previously described as weakly bonded $\mathrm{N}_{2} \mathrm{O}$ with the zeolite. ${ }^{17}$ The peaks centred at 1683,1712 and $1749 \mathrm{~cm}^{-1}$ can be attributed to $\mathrm{N}_{2} \mathrm{O}_{4}$ or $\mathrm{NO}_{2}$. The band at $1749 \mathrm{~cm}^{-1}$ is typical of $\mathrm{N}_{2} \mathrm{O}_{4}$ adsorbed on zeolite acidic hydroxyls, as can be seen this band is more pronounced in case of the reduced and auto-reduced samples, as the bridging $\mathrm{OH}-$ groups can form after the reduction of $\mathrm{Cu}^{2+}$ ions to $\mathrm{Cu}^{0}$. The presence of various $\mathrm{N}_{\mathrm{x}} \mathrm{O}_{\mathrm{y}}$ in the spectra could be explained by NO disproportion. It is known that the following equilibrium exists for $\mathrm{NO}: 3 \mathrm{NO} \leftrightarrow \mathrm{NO}_{2}+\mathrm{N}_{2} \mathrm{O}$, which is shifted to the right at higher pressures. Also, $\mathrm{NO}_{2}$ can easily dimerize to form $\mathrm{N}_{2} \mathrm{O}_{4} \cdot{ }^{14}$

In general, the $\mathrm{NO}$ adsorption on $\mathrm{Cu}^{+}$in the LTL zeolite is similar to the $\mathrm{CO}$ adsorption. There is a significant increase in the amount of $\mathrm{Cu}^{+}$species for the sample prepared in vacuum compared to the one pretreated in $\mathrm{O}_{2}$. For the sample reduced under $\mathrm{H}_{2}$ and $\mathrm{Cu}^{0}$-LTL sample pretreated in vacuum, there is an evident decrease in the intensity of the bands associated with $\mathrm{Cu}^{+}$and $\mathrm{Cu}^{2+}$ species. This can be attributed to the formation of metallic nanoparticles (Cu NPs) that do not interact with NO molecules. However, spectral lines associated to both (1+) and (2+) copper oxidation states are still present.

The adsorption of $\mathrm{NO}$ on the sample $\mathrm{Cu}^{2+}$-LTL treated under oxidative conditions initially results in the interaction of $\mathrm{NO}$ with $\mathrm{Cu}^{2+}$ in different sites. It is followed by the appearance of a vibrational band associated with $\mathrm{Cu}^{+}-\mathrm{NO}$ interactions at higher $\mathrm{NO}$ dose (Figure 5A). For the sample treated under vacuum (Figure 5B) the global intensity of the $\mathrm{Cu}^{2+}-\mathrm{NO}$ 
decreases except for the band at $1886 \mathrm{~cm}^{-1}$ that is associated with the less accessible $\mathrm{Cu}^{2+}$ in planar coordination. In addition, a strong increase of the contributions assigned to the $\mathrm{Cu}^{+}-$ NO species can be observed indicating the reduction of $\mathrm{Cu}^{2+}$ to $\mathrm{Cu}^{+}$copper species. For the sample reduced under $\mathrm{H}_{2}$ or hydrazine, the vibrational spectra contains only a weak contribution from the $\mathrm{Cu}^{2+}$ site and two weak contributions associated with $\mathrm{Cu}^{+}$. This demonstrates that significant amount of the $\mathrm{Cu}^{2+}$ initially present has been reduced to $\mathrm{Cu}^{0}$ metal species. 
(A)

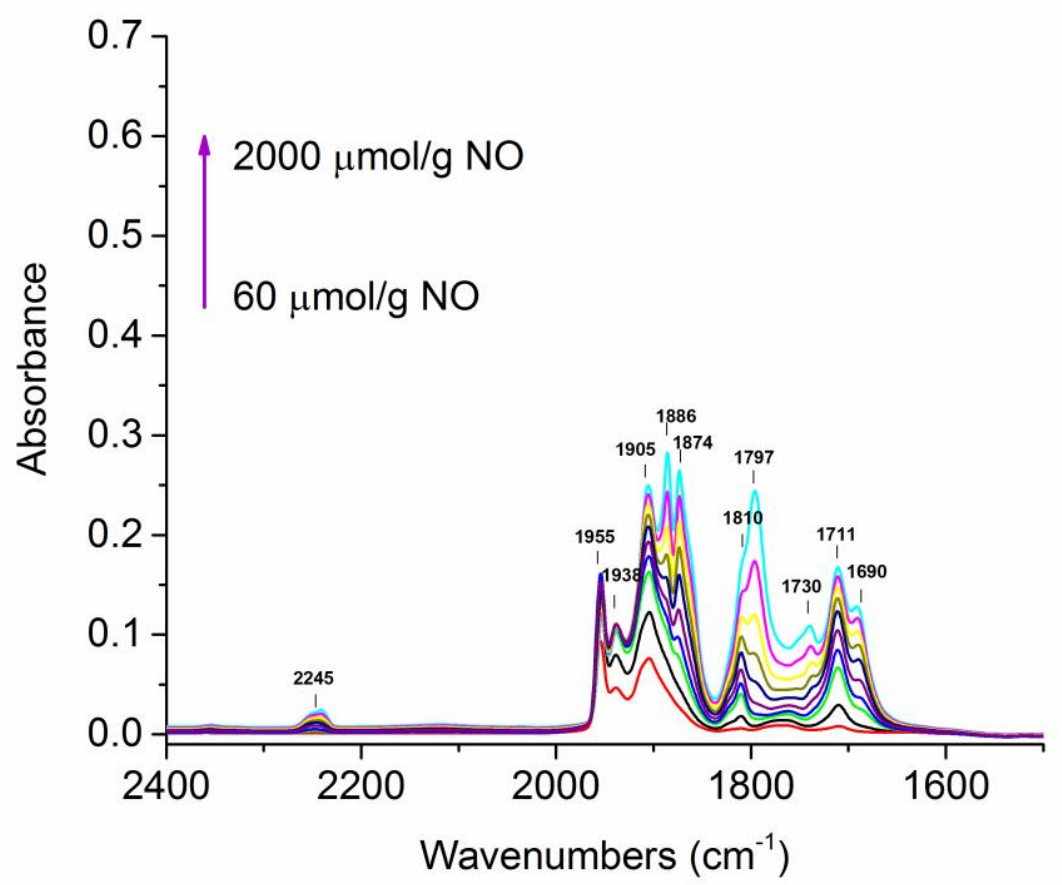

(B)

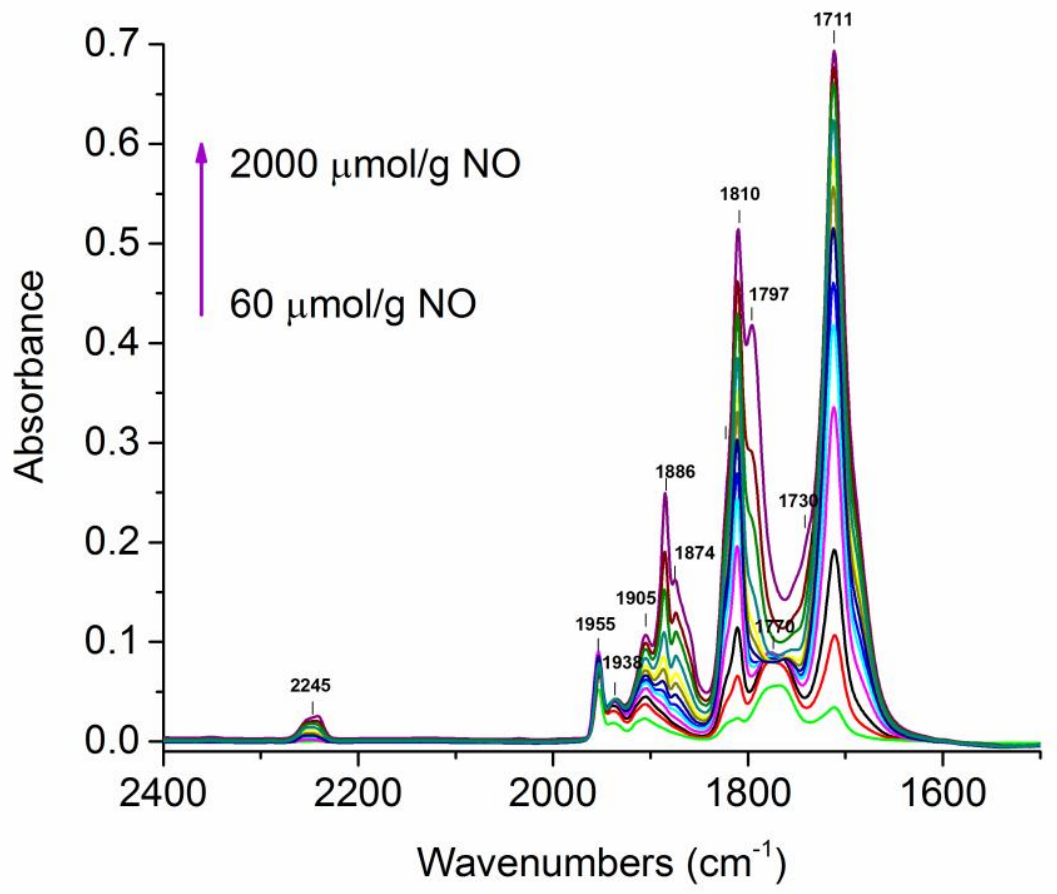


(C)

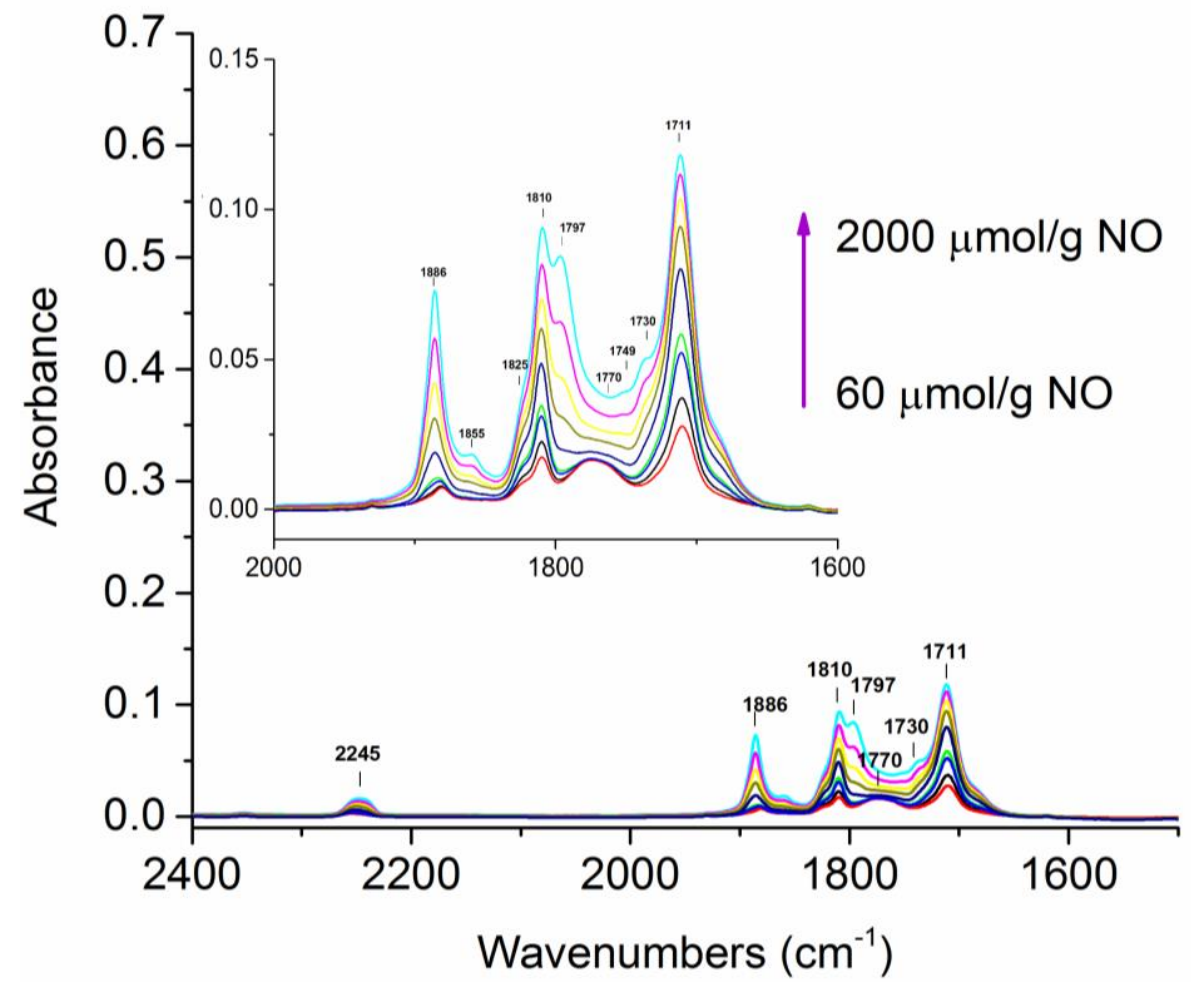

(D)

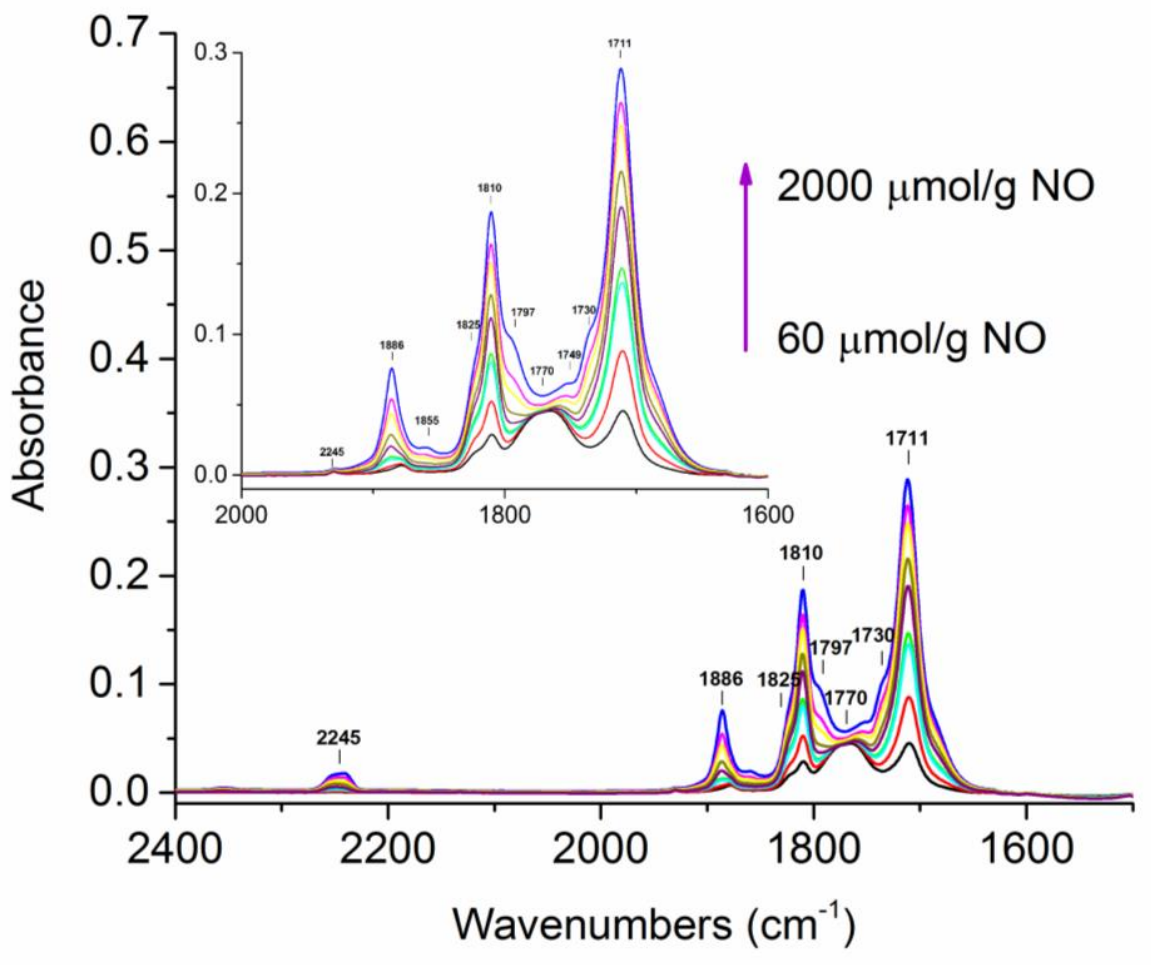

Figure 5 IR spectra $\left(2400-1500 \mathrm{~cm}^{-1}\right)$ of copper containing LTL sample upon interaction with increasing doses of $\mathrm{NO}(60-2000 \mu \mathrm{mol} / \mathrm{g})$ at $100 \mathrm{~K}$. Sample $\mathrm{Cu}^{2+}$-LTL activated at $673 \mathrm{~K}^{2}$ in $\mathrm{O}_{2}(\mathrm{~A})$, in vacuum (B), in $\mathrm{H}_{2}(\mathrm{C})$, and sample $\mathrm{Cu}^{0}$-LTL reduced with $\mathrm{N}_{2} \mathrm{H}_{4}$ activated at $723 \mathrm{~K}$ in vacuum (D). Inserts in (C) and (D): visualization of the peaks by rescaling of the $y$-axis. 
Table 2 Frequencies and assignment of the $\mathrm{N}-\mathrm{O}$ stretching frequencies observed in this study.

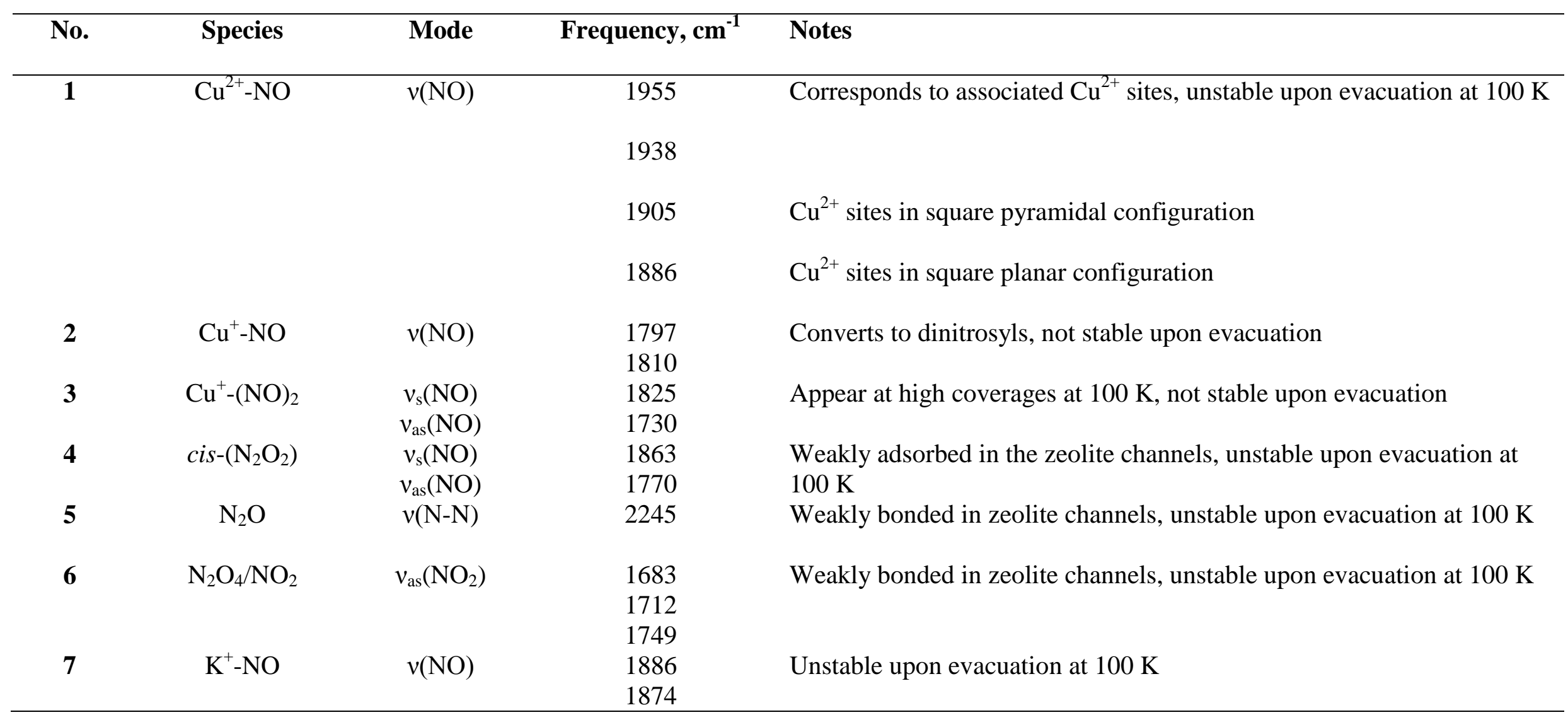




\section{UV-Vis characterization of copper containing zeolite samples}

The self-supported pellets of $\mathrm{Cu}^{2+}$-LTL pretreated in $\mathrm{O}_{2}$ and $\mathrm{Cu}^{0}$-LTL pretreated in vacuum at same temperatures as for the FTIR experiments have been examined using diffuse reflectance UV-Vis spectroscopy (Figure 6). The $\mathrm{Cu}^{2+}$-LTL sample contains absorption bands in the regions $240-450 \mathrm{~nm}$ and $600-800 \mathrm{~nm}$, that are described in the literature as $\mathrm{Cu}^{2+} \leftarrow \mathrm{O}^{2-}$ charge-transfer transitions and $\mathrm{d}-\mathrm{d}$ transitions of isolated distorted octahedral $\mathrm{Cu}^{2+}$ ions, respectively. ${ }^{23,33}$ The presence of metallic copper species in $\mathrm{Cu}^{0}$-LTL sample was revealed by an absorption peak at about $550 \mathrm{~nm}$, which is attributed to surface plasmon (SPR) resonance of the metallic $\mathrm{Cu}{ }^{33,34}$ This sample also shows band at $240 \mathrm{~nm}$ that is already assigned to $\mathrm{Cu}^{2+}$ species. A broad feature between 360 and $430 \mathrm{~nm}$ could be assigned to O$\mathrm{Cu}-\mathrm{O}$ and $\mathrm{Cu}-\mathrm{O}-\mathrm{Cu}$ complexes. ${ }^{35}$

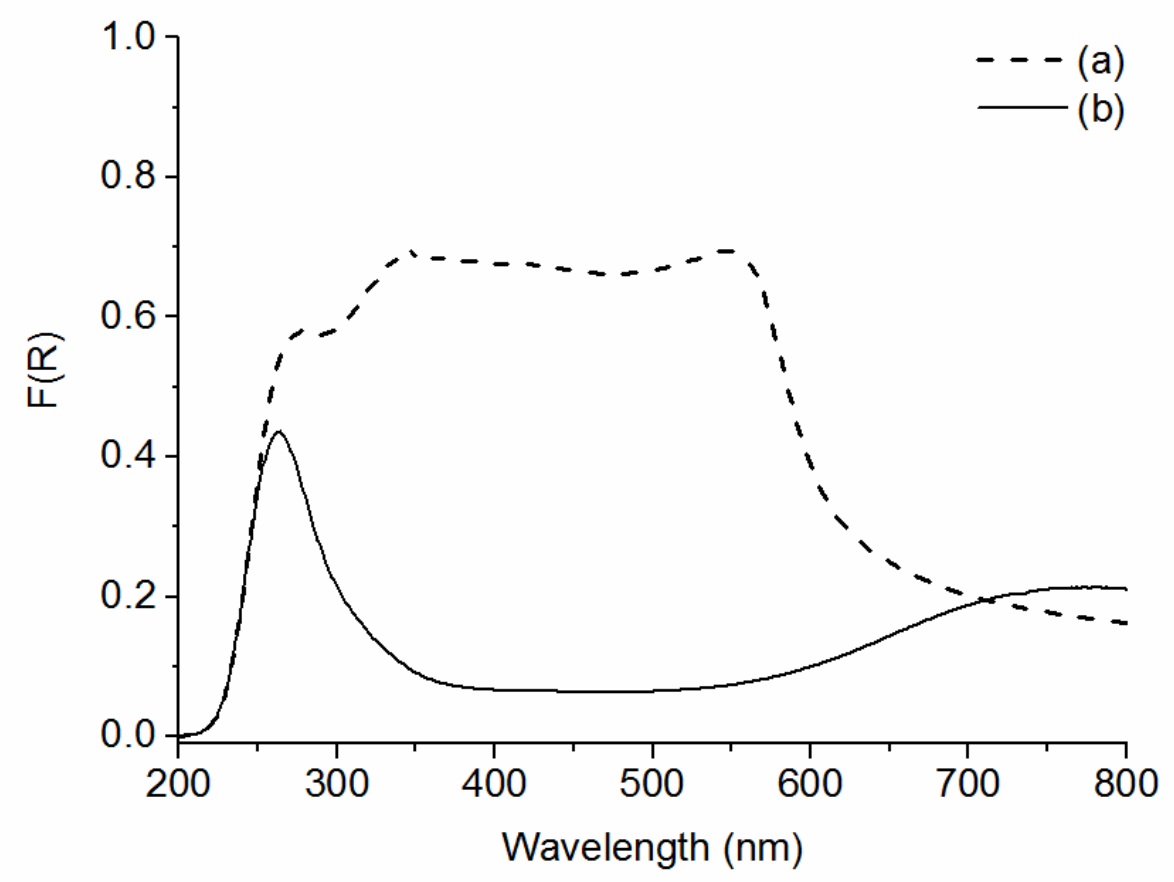

Figure 6 DR UV-Vis spectra of self-supported pellets of (a) $\mathrm{Cu}^{0}$-LTL reduced with $\mathrm{N}_{2} \mathrm{H}_{4}$ activated at $723 \mathrm{~K}$ in vacuum and (b) $\mathrm{Cu}^{2+}$-LTL activated under oxygen atmosphere at $673 \mathrm{~K}$. 


\section{EPR characterization of copper containing zeolites}

EPR spectroscopy can be used for monitoring paramagnetic $\mathrm{Cu}^{2+}$ cations and changes in their local environment, while other copper oxidation states $\left(\mathrm{Cu}^{+}, \mathrm{Cu}^{0}\right)$ are EPR silent. ${ }^{36}$ Figure 7 shows a drastic decrease in the amount of $\mathrm{Cu}^{2+}$ species upon reduction and partial reoxidation under calcination in air. Rasia et al. have shown the correlation between the hyperfine coupling constant $\mathrm{A}_{/ /}$and $\mathrm{g}$-factor $\left(\mathrm{g}_{/ /}\right)$in the EPR spectra of $\mathrm{Cu}(\mathrm{II})$ complexes. ${ }^{37}$ The changing values of these parameters can be used to determine the type of ligands coordinated to $\mathrm{Cu}^{2+}$ ions at different stages. According to the correlation diagram established by Rasia et al. the starting $\mathrm{Cu}^{2+}$-LTL sample contains copper coordinated to four oxygen atoms, while after the hydrazine treatment, the unreduced copper species are coordinated to both nitrogen from hydrazine and oxygen atoms from the zeolite framework (Table 3 ). These observations are in good agreement with previous reports, which describe $\mathrm{Cu}^{2+}$ closely interacting with four framework oxygen atoms in the 6MR's ring. ${ }^{38}$

Table 3 The values of hyperfine coupling constant $\mathrm{A}_{/ /}$and $\mathrm{g}$-factor $\left(\mathrm{g}_{/ /}\right)$obtained from EPR spectra of copper containing zeolite samples.

\begin{tabular}{ccc}
\hline Sample & \multicolumn{2}{c}{ Spin Hamiltonian Parameters } \\
\cline { 2 - 3 } & $\mathrm{g}_{/ /}$ & $\mathrm{A}_{/ /}$ \\
$\mathbf{C u}^{2+}$-LTL & 2.4 & 132 \\
$\mathbf{C u}^{\mathbf{0}}$-LTL & 2.27 & 177 \\
$\mathbf{C u}^{\mathbf{0}}$-LTL-reox & 2.39 & 130 \\
\hline
\end{tabular}




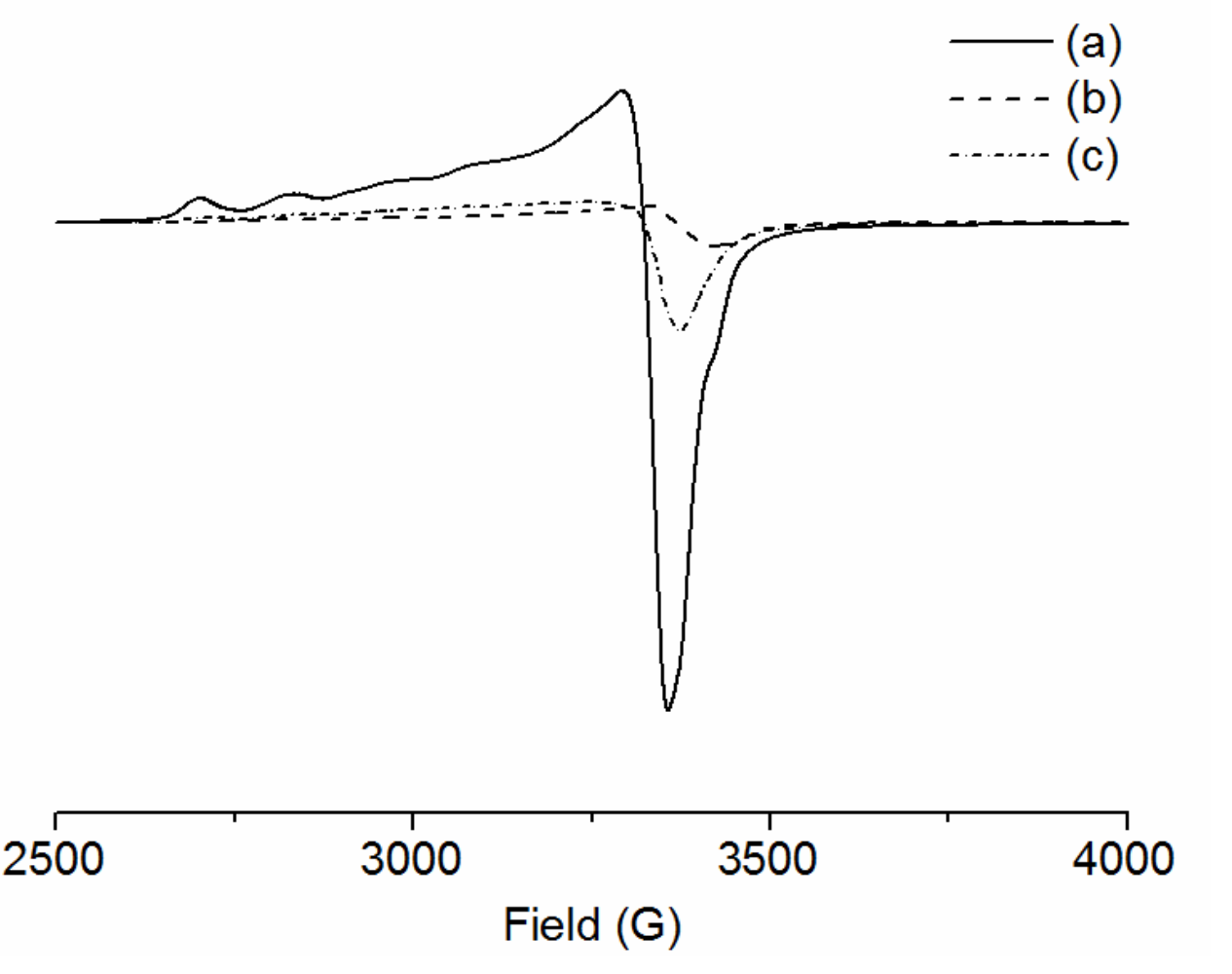

Figure 7 EPR spectra of $\mathrm{Cu}^{2+}$-LTL sample upon reduction and thermal treatment in air (a) $\mathrm{Cu}^{2+}$ - LTL, (b) $\mathrm{Cu}^{0}-\mathrm{LTL}$, and (c) $\mathrm{Cu}^{0}-\mathrm{LTL}$ reoxidized sample.

\section{${ }^{29} \mathrm{Si}$ and ${ }^{63} \mathrm{Cu}$ MAS NMR characterization of copper containing zeolites}

Owing to the low natural abundance of $4.7 \%$ and a long spin-lattice relaxation time (T1) of ${ }^{29} \mathrm{Si}$ nuclei, the ${ }^{29} \mathrm{Si}$ MAS NMR measurements of porous silicates require long measuring time. While T1 varies from a few microseconds to around $30 \mathrm{~s}$ for most of the zeolites, it can reach 5000 seconds in layered silicate nacrite. ${ }^{39}$ However, it has been shown that the introduction of paramagnetic centres into mesoporous and microporous silicate crystals significantly shortens the relaxation time due to a more effective nuclear relaxation by direct interaction between the ${ }^{29} \mathrm{Si}$ nucleus and the electron spin. ${ }^{39,40}$ Hence, the measurement of the relaxation rate changes in ${ }^{29} \mathrm{Si}$ MAS NMR signal of copper-doped LTL zeolite should allow monitoring the degree of reduction of $\mathrm{Cu}^{2+}$ cations.

The ${ }^{29} \mathrm{Si}$ MAS spectra of parent LTL, $\mathrm{Cu}^{2+}$-LTL and $\mathrm{Cu}^{0}$-LTL samples are shown in Figure 8. Five peaks at $-88,-90,-96,-101$, and $-106 \mathrm{ppm}$ are assigned to $\mathrm{Si}(0 \mathrm{Si} 4 \mathrm{Al}), \mathrm{Si}(1 \mathrm{Si} \mathrm{Al})$, Si(2Si2Al), Si(3Si1Al), Si(4Si0Al), respectively. ${ }^{41}$ The T1 values for different sites in the 
parent LTL and copper doped zeolites are summarized in Table 4. As can be seen, ${ }^{29} \mathrm{Si} \mathrm{T} 1$ values of different silica sites in the parent zeolite are in the range of 9-12 s, while after the introduction of 1 paramagnetic $\mathrm{Cu}^{2+}$ ion per unit cell, the relaxation rate decreases drastically. The analysis of the $\mathrm{T} 1$ values for different $\mathrm{Si}$ sites can be utilized to indicate the preferred coordination sites for $\mathrm{Cu}^{2+}$ cations. The enhancement of relaxation (which corresponds to lower values of $\mathrm{T} 1)$ follows the order $\operatorname{Si}(4 \mathrm{Al})>\operatorname{Si}(3 \mathrm{Al})>\operatorname{Si}(2 \mathrm{Al}) \geq \operatorname{Si}(\mathrm{A} 1) \geq \operatorname{Si}(0 \mathrm{Al})$, suggesting that the most favourable coordination sites for $\mathrm{Cu}^{2+}$ species are $\mathrm{Si}(4 \mathrm{Al})$ and $\mathrm{Si}(3 \mathrm{Al})$. For the zeolites containing reduced copper, the relaxation time has the values of the same order of magnitude as for the parent LTL sample. These results suggest a significant decrease in the amount of paramagnetic $\mathrm{Cu}^{2+}$ species in the reduced sample.

Table 4 Relaxation time (T1) of different $\mathrm{Q}_{\mathrm{n}}$ sites in the LTL and Cu-LTL zeolite samples.

\begin{tabular}{cccc}
\hline Sites & \multicolumn{1}{c}{ T1(s) } & \\
\hline & Parent LTL & $\mathbf{C u}^{2+}$-LTL & $\mathbf{C u}^{\mathbf{0}}$-LTL \\
$\mathbf{Q}_{\mathbf{4}}(\mathbf{4 A l})$ & 11.6 & $2.9 \times 10^{-2}$ & 23.3 \\
$\mathbf{Q}_{\mathbf{4}}(\mathbf{3 A l})$ & 10.0 & $5.5 \times 10^{-2}$ & 19.0 \\
$\mathbf{Q}_{\mathbf{4}}(\mathbf{2} \mathbf{A l})$ & 9.2 & $8.4 \times 10^{-2}$ & 13.9 \\
$\mathbf{Q}_{\mathbf{4}}(\mathbf{1} \mathbf{A l})$ & 9.2 & $9.2 \times 10^{-2}$ & 12.3 \\
$\mathbf{Q}_{\mathbf{4}}(\mathbf{0 A l})$ & 9.1 & $8.5 \times 10^{-2}$ & 12.0 \\
\hline
\end{tabular}




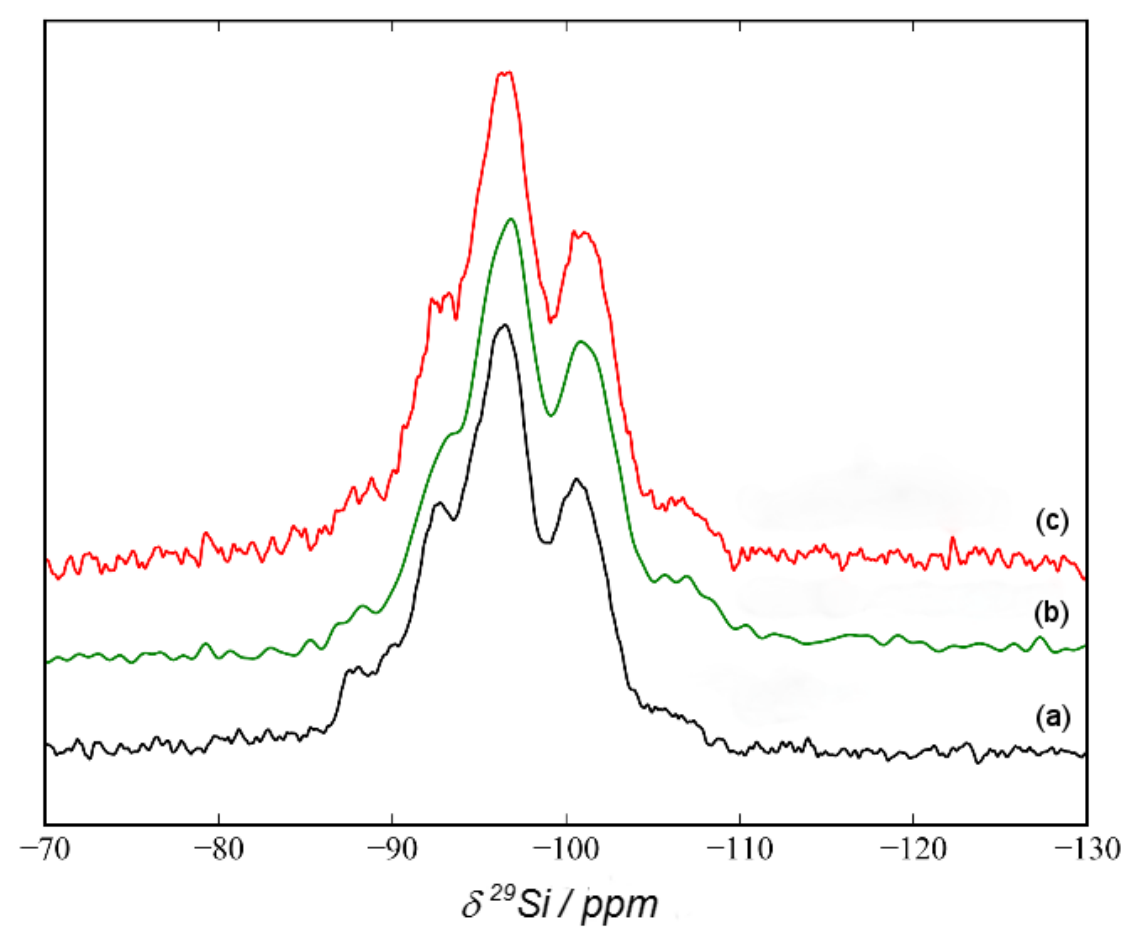

Figure $8{ }^{29} \mathrm{Si}$ MAS NMR spectra of (a) parent LTL, (b) $\mathrm{Cu}^{2+}$-LTL and (c) $\mathrm{Cu}^{0}-\mathrm{LTL}$ samples.

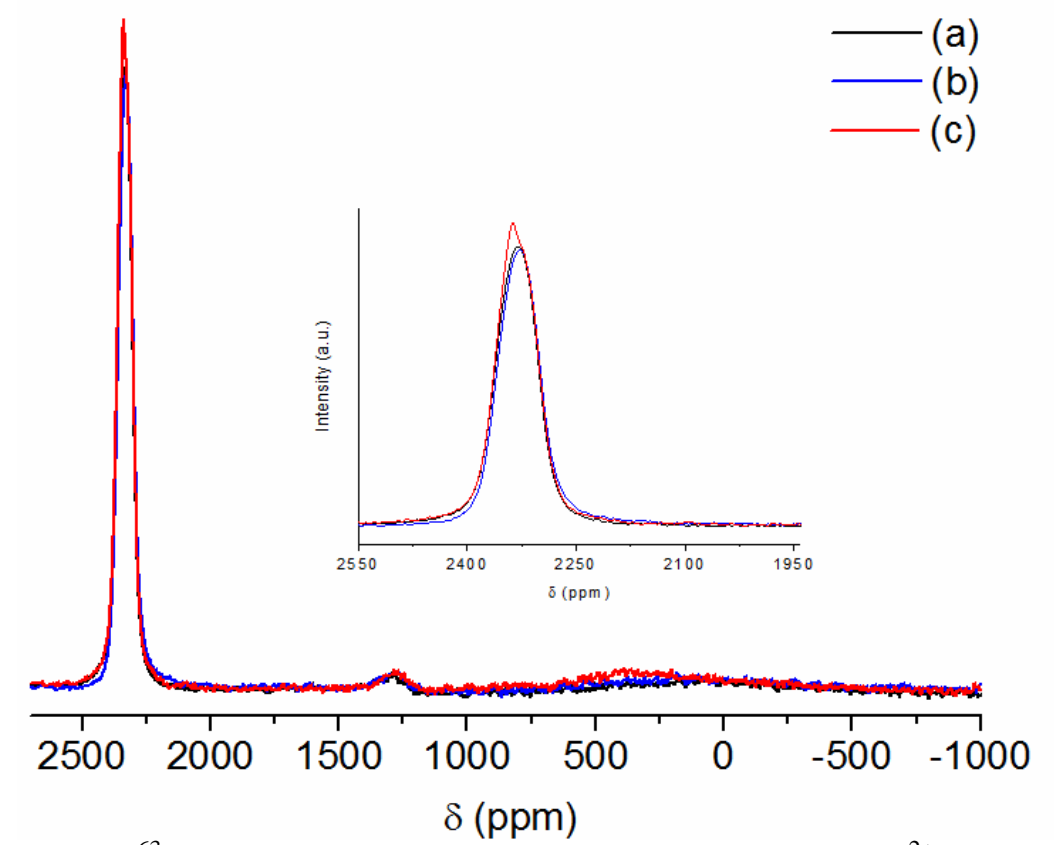

Figure $9{ }^{63} \mathrm{Cu}$ MAS NMR spectra of (a) parent LTL, (b) $\mathrm{Cu}^{2+}$-LTL and (c) $\mathrm{Cu}^{0}$-LTL samples.

The reduced $\mathrm{Cu}^{0}$-LTL sample has been also examined by ${ }^{63} \mathrm{Cu}$ MAS NMR spectroscopy. The anisotropic resonance at $2330 \mathrm{ppm}$ prevails in the ${ }^{63} \mathrm{Cu}$ NMR spectra of the parent LTL and $\mathrm{Cu}^{2+}$-LTL samples, which arises due to the $\mathrm{Cu}$ radio frequency coil in the probe (Figure 9). No other signals are observed in these materials. Two extra resonances at $2340 \mathrm{ppm}$ and 360 
ppm are detected in the spectrum of $\mathrm{Cu}^{0}$-LTL sample. The peak at $2340 \mathrm{ppm}$ that is resolved from the peak of the $\mathrm{Cu}$ coil (at $2330 \mathrm{ppm}$ ) has been previously assigned to metal $\mathrm{Cu}$ particles. ${ }^{42}$ It has been shown by FTIR that the $\mathrm{Cu}^{0}$-LTL sample contains $\mathrm{Cu}^{+}$species, and therefore, the peak at $360 \mathrm{ppm}$ can be assigned to $\mathrm{Cu}^{+}$. 


\section{Conclusions}

The examination of oxidation states of supported copper species in LTL nanosized zeolites utilizing a range of characterization techniques demonstrates that the reduction of copper is a complex process, involving different species such as $\mathrm{Cu}^{2+}, \mathrm{Cu}^{+}$and $\mathrm{Cu}$ NPs in different locations. Adsorption of $\mathrm{NO}$ and $\mathrm{CO}$ allows quantitative monitoring of the modifications in the copper containing LTL zeolite upon oxidation and reduction, as both the $\mathrm{Cu}^{2+}$ and $\mathrm{Cu}^{+}$ can be selectively probed. The FTIR results indicate the heterogeneity of $\mathrm{Cu}^{2+}$ and $\mathrm{Cu}^{+}$ cations in the $\mathrm{Cu}-\mathrm{LTL}$ zeolite prepared by ion-exchange procedure. Furthermore, quantitative analysis of the data obtained from the $\mathrm{CO}$ adsorption followed by FTIR spectroscopy shows that the relative amount of copper in (1+) state is about $43 \%$. This agrees with the amount of copper nanoparticles $\left(\mathrm{Cu}^{0}\right)$ determined by $\mathrm{UV}-\mathrm{V}$ is measurement (about 55\%). The reduction of $\mathrm{Cu}^{2+}$ species and the presence of copper cations and $\mathrm{Cu}^{0}$ have been also confirmed by adsorption of NO, ${ }^{29} \mathrm{Si}$ MAS NMR and EPR. The ${ }^{29} \mathrm{Si}$ MAS spectra showed that the most

favourable coordination sites for $\mathrm{Cu}^{2+}$ species are $\mathrm{Si}(4 \mathrm{Al})$ and $\mathrm{Si}(3 \mathrm{Al})$, while the ${ }^{63} \mathrm{Cu}$ MAS NMR verified the presence of copper nanoparticles $\left(\mathrm{Cu}^{0}\right)$. 


\section{Acknowledgements}

We acknowledge the financial support provided by TAR-G-ED ANR project.

\section{Notes and references}

1 W. Sheng, Curr. Org. Chem., 2011, 15, 3692-3705.

2 M. Hitrik, A. Dandapat, Y. Sasson, A. G. Livingston, K. K. Hii, G. Strukul, E. J. Mozeleski, D. W. Brown and E. M. Staudt, RSC Adv., 2016, 6, 68041-68048.

3 T. V. W. Janssens, H. Falsig, L. F. Lundegaard, P. N. R. Vennestrøm, S. B. Rasmussen, P. G. Moses, F. Giordanino, E. Borfecchia, K. A. Lomachenko, C. Lamberti, S. Bordiga, A. Godiksen, S. Mossin and P. Beato, ACS Catal., 2015, 5, $2832-2845$.

4 D. Farrusseng and A. Tuel, New J. Chem., 2016, 40, 3933-3949.

$5 \quad$ Y. Sun, Chem. Soc. Rev., 2013, 2497-2511.

$6 \quad$ Y. Sun, Mater. Today, 2012, 15, 140-147.

7 S. Wang, X. Huang, Y. He, H. Huang, Y. Wu, L. Hou, X. Liu, T. Yang, J. Zou and B. Huang, Carbon N. Y., 2012, 50, 2119-2125.

8 Y. Lu, W. Wei and W. Chen, Chinese Sci. Bull., 2012, 57, 41-47.

9 J. Kecht, Z. Tahri, V. De Waele, M. Mostafavi, S. Mintova and T. Bein, Chem. Mater., 2006, 18, 3373-3380.

10 J. Shi, Y. Wang, W. Yang, Y. Tang and Z. Xie, Chem. Soc. Rev., 2015, 44, 88778903.

11 S. Mintova, M. Jaber and V. Valtchev, Chem. Soc. Rev., 2015, 44, 7207-7233.

12 A. Kharchenko, O. I. Lebedev, V. Zholobenko, V. de Waele and S. Mintova, J. Phys. Chem. C, 2016, 120, 26300-26308.

13 K. I. Hadjiivanov, Adv. Catal., 2002, 47, 307-511. 
14 K. Hadjiivanov, Catal. Rev., 2000, 42, 71-144.

15 A. Vimont, F. Thibault-Starzyk and M. Daturi, Chem. Soc. Rev., 2010, 39, 4928-4950.

16 S. Bordiga, C. Lamberti, F. Bonino, A. Travert and F. Thibault-Starzyk, Chem. Soc. Rev., 2015, 44, 7262-7341.

17 C. Lamberti, A. Zecchina, E. Groppo and S. Bordiga, Chem. Soc. Rev., 2010, 39, $4951-5001$

18 G. T. Kerr, J. Phys. Chem., 1969, 73, 2780-2782.

19 K. Hadjiivanov and H. Knozinger, Phys. Chem. Chem. Phys., 2001, 3, 1132-1137.

20 K. Hadjiivanov, J. Catal., 2000, 191, 480-485.

21 M. M. Kantcheva and K. I. Hadjiivanov, 1992, 55, 49-55.

22 J. Howard and J. M. Nicol, Zeolites, 1988, 8, 142-150.

23 A. Gallo, T. Tsoncheva, M. Marelli, M. Mihaylov, M. Dimitrov, V. Dal Santo and K. Hadjiivanov, Appl. Catal. B Environ., 2012, 126, 161-171.

24 G. Turnes Palomino, C. Otero Areán, F. Geobaldo, G. Ricchiardi, S. Bordiga and A. Zecchina, J. Chem. Soc. Faraday Trans., 1997, 93, 189-191.

25 E. Borfecchia, K. A. Lomachenko, F. Giordanino, H. Falsig, P. Beato, A. V. Soldatov, S. Bordiga and C. Lamberti, Chem. Sci., 2014, 8, 548-563.

26 G. T. Palomino, P. Fisicaro, S. Bordiga, A. Zecchina, E. Giamello and C. Lamberti, J. Phys. Chem. B, 2000, 104, 4064-4073.

27 V. Zdravkova, N. Drenchev, E. Ivanova, M. Mihaylov and K. Hadjiivanov, J. Phys. Chem. C, 2015, 119, 15292-15302.

28 P. Kaminski, I. Sobczak, P. Decyk, M. Ziolek, W. J. Roth, B. Campo and M. Daturi, J. Phys. Chem. C, 2013, 117, 2147-2159.

29 M. Tortorelli, K. Chakarova, L. Lisi and K. Hadjiivanov, J. Catal., 2014, 309, 376385. 
31 I. Sobczak, M. Ziolek, M. Renn, P. Decyk, I. Nowak, M. Daturi and J. C. Lavalley, Microporous Mesoporous Mater., 2004, 74, 23-36.

32 A. Penkova, K. Hadjiivanov, M. Mihaylov, M. Daturi, J. Saussey and J.-C. Lavalley, Lagmuir, 2004, 20, 5425-5431.

33 D. Esquivel, A. J. Cruz-Cabeza, C. Jiménez-Sanchidrián and F. J. Romero-Salguero, Microporous Mesoporous Mater., 2013, 179, 30-39.

34 U. Kreibig, M. Quinten and D. Schoenauer, Optical Properties of Nanoparticle Systems, 1986, vol. T13.

35 A. N. Pestryakov, V. P. Petranovskii, A. Kryazhov, O. Ozhereliev, N. Pfaender and A. Knop-Gericke, Chem. Phys. Lett., 2004, 385, 173-176.

36 U. Deka, I. Lezcano-Gonzalez, B. M. Weckhuysen and A. M. Beale, ACS Catal., $2013,3,413-427$.

37 R. M. Rasia, C. W. Bertoncini, D. Marsh, W. Hoyer, D. Cherny, M. Zweckstetter, C. Griesinger, T. M. Jovin and C. O. Fernández, Proc. Natl. Acad. Sci. U. S. A., 2005, 102, 4294-4299.

38 R. A. Schoonheydt, Catal. Rev. Sci. Eng., 1993, 35, 129-168.

39 S. Inagaki, I. Kawamura, Y. Sasaki, K. Yoshida, Y. Kubota and A. Naito, Phys. Chem. Chem. Phys., 2013, 15, 13523-13531.

40 L. Zhou, S. Li, Y. Su, B. Li and F. Deng, Solid State Nucl. Magn. Reson., 2015, 66-67, $29-32$.

41 L. Mafra, J. A. Vidal-Moya and T. Blasco, Annual Reports on NMR Spectroscopy, 2012, vol. 77 .

42 N. Yamakawa, M. Jiang and C. P. Grey, Chem. Mater., 2009, 21, 3162-3176. 
TOC:

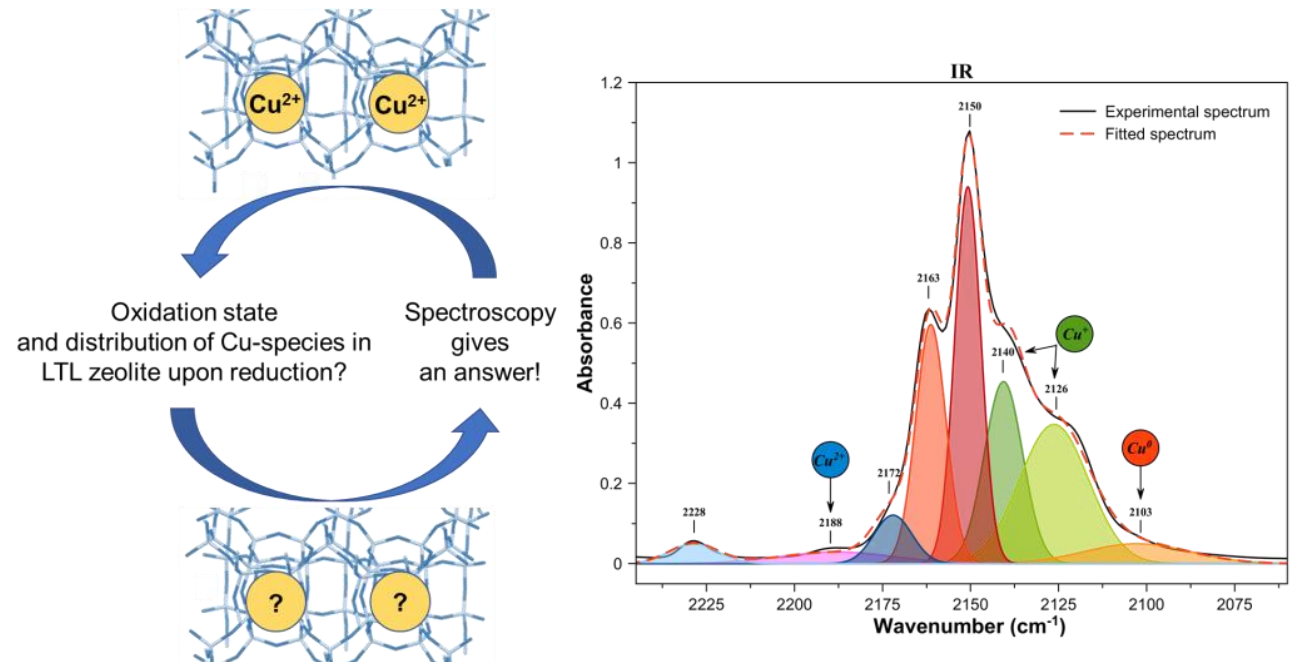

